\title{
Effects of coupling a stochastic convective parameterization with the Zhang-McFarlane scheme on precipitation simulation in the DOE E3SMv1.0 atmosphere model
}

\author{
Yong Wang ${ }^{1}$, Guang J. Zhang ${ }^{2}$, Shaocheng Xie ${ }^{3}$, Wuyin Lin ${ }^{4}$, George C. Craig ${ }^{5}$, Qi Tang ${ }^{3}$, and Hsi-Yen Ma ${ }^{3}$ \\ ${ }^{1}$ Ministry of Education Key Laboratory for Earth System Modeling \& Department of Earth System Science, \\ Tsinghua University, Beijing, 100084, China \\ ${ }^{2}$ Scripps Institution of Oceanography, La Jolla, CA, USA \\ ${ }^{3}$ Lawrence Livermore National Laboratory, Livermore, CA, USA \\ ${ }^{4}$ Brookhaven National Laboratory, Upton, NY, USA \\ ${ }^{5}$ Meteorologisches Institut, Ludwig-Maximilians-Universität, Munich, Germany
}

Correspondence: Guang J. Zhang (gzhang@ucsd.edu)

Received: 28 July 2020 - Discussion started: 29 September 2020

Revised: 5 February 2021 - Accepted: 13 February 2021 - Published: 18 March 2021

\begin{abstract}
A stochastic deep convection parameterization is implemented into the US Department of Energy (DOE) Energy Exascale Earth System Model (E3SM) Atmosphere Model version 1.0 (EAMv1). This study evaluates its performance in simulating precipitation. Compared to the default model, the probability distribution function (PDF) of rainfall intensity in the new simulation is greatly improved. The wellknown problem of "too much light rain and too little heavy rain" is alleviated, especially over the tropics. As a result, the contribution from different rain rates to the total precipitation amount is shifted toward heavier rain. The less frequent occurrence of convection contributes to suppressed light rain, while more intense large-scale and convective precipitation contributes to enhanced heavy total rain. The synoptic and intraseasonal variabilities of precipitation are enhanced as well to be closer to observations. The sensitivity of the rainfall intensity PDF to the model vertical resolution is examined. The relationship between precipitation and dilute convective available potential energy in the stochastic simulation agrees better with that in the Atmospheric Radiation Measurement (ARM) observations compared with the standard model simulation. The annual mean precipitation is largely unchanged with the use of the stochastic scheme except over the tropical western Pacific, where a moderate increase in precipitation represents a slight improvement. The responses of precipita-
\end{abstract}

tion and its extremes to climate warming are similar with or without the stochastic deep convection scheme.

\section{Introduction}

Precipitation plays a vital role in the Earth's climate: the latent heat released during precipitation formation is a major energy source that drives the atmospheric circulation, and precipitation is an important part of the Earth's hydrological cycle. The accurate simulation of precipitation in global climate models (GCMs) is of great scientific and societal interest. However, GCMs used for current climate simulation and future projections suffer from many biases in the global distribution, frequency and intensity of simulated precipitation (Dai, 2006), which have negatively impacted the model's fidelity. Rainfall in nature is tightly associated with many complex dynamic and physical processes in the atmosphere, including large-scale circulation, convection, cloud microphysics and planetary boundary layer (PBL) processes. The deficiencies in representing these processes in GCMs are prime culprits for errors in simulated rainfall (Watson et al., 2017).

Among the physical processes in GCMs, the parameterization of convection is responsible for some well-known biases: the double Intertropical Convergence Zone (Zhang and 
Wang, 2006; Zhang et al., 2019), synoptic and intraseasonal variabilities in the tropics that are too weak (Zhang and $\mathrm{Mu}$, 2005a; Watson et al., 2017), the wrong diurnal cycle of rainfall (Xie et al., 2019), and "too much light rain and too little heavy rain" (Dai, 2006; Zhang and Mu, 2005b; O'Gorman and Schneider, 2009) to name a few. The conventional deterministic convective parameterization in GCMs represents the ensemble effects of subgrid-scale convective clouds in a model grid box on resolved scale variables. However, in reality, a given grid-scale state may lead to different realizations of subgrid-scale convection (Davies et al., 2013; Peters et al., 2013) rather than to a single "ensemble mean" response. For instance, two model grid boxes, both in a similar convective equilibrium state, can have different numbers and/or sizes of convective clouds due to stochasticity (Cohen and Craig, 2006). This stochasticity will appear more frequently as the model grid box size becomes smaller (Jones and Randall, 2011). Not including stochasticity in convective schemes has been suggested to be at least partly responsible for the weak intraseasonal variability and "too much light rain and too little heavy rain" in GCMs (Lin and Neelin, 2000; Wang et al., 2016; Watson et al., 2017; Peters et al., 2017).

As suggested in Palmer $(2001,2012)$, more realistic statistics of the impacts of subgrid convective clouds should be derived by simulating them as random samples from probability distributions conditioned on the grid-scale state so that the influences of different individual realizations are introduced in the convection parameterization. In this regard, much effort in the past 2 decades has been made to develop stochastic convection schemes (e.g., Lin and Neelin, 2000, 2002; Plant and Craig, 2008; Khouider et al., 2010; Sakradzija et al., 2015). Among these schemes, Plant and Craig (2008) (PC08 hereafter) developed a stochastic deep convection parameterization under a framework based on statistical mechanics (Cohen and Craig, 2006; Craig and Cohen, 2006) for noninteracting convective clouds in statistical equilibrium using cloud-resolving model (CRM) simulations. This scheme was applied to numerical weather prediction (NWP) models and to a GCM in an aquaplanet setting, resulting in some substantial improvements in precipitation simulation (Groenemeijer and Craig, 2012; Keane et al., 2014, 2016).

Wang et al. (2016) incorporated the PC08 stochastic deep convection scheme into the Zhang-McFarlane (ZM) deterministic deep convection scheme (Zhang and McFarlane, 1995) in the National Center for Atmospheric Research (NCAR) Community Atmosphere Model version 5 (CAM5). They found that the introduction of the stochastic scheme improved the simulation of precipitation intensity and intraseasonal variability over the tropics in CAM5 (Wang and Zhang, 2016; Wang et al., 2017).

In this study, we implement the PC08 stochastic deep convection parameterization scheme into the DOE Energy Exascale Earth System Model (E3SM) (Golaz et al., 2019) Atmosphere Model version 1.0 (EAMv1) (Rasch et al., 2019; Xie et al., 2018) and examine its effect on precipitation simula- tion. The EAMv1 is branched out from CAM5, and it thus inherits many model deficiencies from CAM5 as well. Many modifications in physics parameterizations have been made compared to CAM5 (Rasch et al., 2019; Xie et al., 2018). However, some model biases, such as weak precipitation intensity, persist (Xie et al., 2019). Thus, besides the precipitation metrics explored in our previous studies (Wang et al., 2016, 2017; Wang and Zhang, 2016), this study will evaluate precipitation simulation with more systematical metrics. In addition, the responses of precipitation and its extremes to climate warming with the stochastic deep convection scheme will be investigated.

The organization of the paper is as follows. Section 2 presents the parameterization, model, experimental design and evaluation data. Section 3 describes results, including variability, frequency, intensity, amounts, duration, mean state, and the responses of precipitation and its extremes to climate warming. The sensitivity of the rainfall intensity PDF to vertical resolution and underlying mechanisms are also presented in this section. A summary is given in Sect. 4.

\section{Parameterization, model, experimental design and evaluation data}

\subsection{Stochastic deep convection parameterization}

The stochastic convective parameterization scheme of PC08 is modified for climate models when incorporating it into the ZM deterministic deep convection scheme. The most essential part of the PC08 scheme involves two probability distributions. One is the probability distribution of mass flux of a cloud; it follows the exponential distribution

$p(m) \mathrm{d} m=\frac{1}{\langle m\rangle} e^{-m /\langle m\rangle} \mathrm{d} m$,

where $\langle m\rangle$ is the mean mass flux of a cloud and is a preset tuning parameter. The integral of the probability density over all values of mass flux is 1, i.e., the probability of 1 that every cloud has a mass flux between zero and infinity. The other is the probability of triggering $n$ clouds for a given cloud mass flux in the range between $m$ and $m+\mathrm{d} m$ at a given GCM grid box and time step; it is drawn from a Poisson distribution:

$P_{\langle N\rangle}(n)=\frac{\langle N\rangle^{n} e^{-\langle N\rangle}}{n !}$ for $n=0,1,2,3 \ldots$,

where $\langle N\rangle$ is the ensemble mean number of convective clouds in the grid box. Here the sum of the probabilities over all $n$ must equal 1, i.e., the probability of 1 that some number between zero and an infinite number of clouds will be triggered with mass flux in this interval. Thus, the average number of clouds with mass flux between $m$ and $m+\mathrm{d} m$, $d \bar{n}(m)$, is

$\mathrm{d} \bar{n}(m)=\langle N\rangle p(m) \mathrm{d} m=\frac{\langle N\rangle}{\langle m\rangle} e^{-m /\langle m\rangle} \mathrm{d} m$. 
From Eqs. (2) and (3), it follows then that for small $\mathrm{d} \bar{n}(m)$ the probability of launching one convective cloud with mass flux between $m$ and $m+\mathrm{d} m$ is given by

$p_{\mathrm{d} \bar{n}(m)}(n=1)=\frac{\langle N\rangle}{\langle m\rangle} e^{-m /\langle m\rangle} \mathrm{d} m$.

Note that Eq. (4) is not a probability density function, but rather the probability of triggering one cloud for a given cloud mass flux interval $(m, m+\mathrm{d} m)$, knowing that the average number of clouds within this mass flux interval is $\mathrm{d} \bar{n}(m) .\langle N\rangle=\langle M\rangle /\langle m\rangle$, where $\langle M\rangle$ is the ensemble mean total cloud mass flux given by the closure based on the convective quasi-equilibrium assumption in the ZM deterministic parameterization. For each mass flux bin, whether to launch a cloud is determined by comparing the probability $\frac{1}{\langle m\rangle} e^{-\frac{m}{\langle m\rangle}} \mathrm{d} m$ with a random number uniformly generated between zero and 1. Then, the sum of mass fluxes generated this way is multiplied by the factor $\langle N\rangle$ to rescale it to the mass flux of all clouds. The product of the total mass flux and the temperature and moisture tendencies from the bulk plume model gives the final temperature and moisture tendencies by the subgrid convective clouds.

There are two modifications to the original implementation in the NCAR CAM5. One is the update frequency of random numbers, which, unlike the update frequency of once a day in Wang et al. (2016), is updated every $3 \mathrm{~d}$ in consideration of computational resources due to finer vertical and horizontal resolutions in the EAMv1 (see Sect. 2.2). For the same reason, the spatial averaging of input quantities (i.e., vertical profiles of temperature and moisture) to the closure over neighboring grid points used in the original design of PC08 is not performed because it leads to an excessive communication load. One can argue that at a horizontal model resolution of about $110 \mathrm{~km}$ in EAMv1, convective quasi-equilibrium approximately holds over some timescale, although at individual model time steps it does not. Thus, although spatial averaging is not applied, the temporal trailing averaging over $3 \mathrm{~h}$ at each time step is retained in the scheme. Other modifications to the PC08 scheme for incorporation into the ZM scheme in climate models (Wang et al., 2016) are retained. These include the following.

1. The temporally averaged quantities are used to calculate the ensemble mean cloud mass flux $(\langle M\rangle)$, which is determined by the ZM scheme. The unsmoothed grid point quantities are still used in the trigger function and the cloud model.

2. The root mean squared cloud radius information originally used in PC08 is not needed in our implementation because the ZM scheme does not use cloud radius.

3. The ensemble mean mass flux of a cloud $\langle m\rangle$ is set to $1 \times 10^{7} \mathrm{~kg} \mathrm{~s}^{-1}$ following Groenemeijer and Craig (2012).
4. The cloud life cycle effect with a factor $\mathrm{d} t / T(\mathrm{~d} t$ is the model time step and $T$ is the constant lifetime parameter) in PC08 is not taken into account because the ZM deterministic parameterization does not consider the life cycle of convection.

\subsection{EAMv1 model}

The standard configuration of the DOE EAMv1 uses a spectral element dynamical core at a $110 \mathrm{~km}$ horizontal resolution on a cubed sphere geometry and a vertical resolution of 72 layers from the surface to $60 \mathrm{~km}(10 \mathrm{~Pa})$ (Rasch et al., 2019; Xie et al., 2018). The treatments of PBL turbulence, shallow convection and cloud macrophysics are unified with a simplified third-order turbulence closure parameterization, CLUBB (Cloud Layers Unified by Binormals; Golaz et al., 2002; Larson and Golaz, 2005). The deep convection is represented by the ZM scheme. The Morrison and Gettelman (2008) (MG) microphysics scheme is updated to MG2 (Gettelman et al., 2015) with the prediction of rain and changes to ice nucleation and ice microphysics (Wang et al., 2014). A four-mode version of the modal aerosol module (MAM4) (Liu et al., 2016) is used with improvements to aerosol resuspension, aerosol nucleation, scavenging, convective transport and sea spray emissions for including the contribution of marine ecosystems to organic matter (Rasch et al., 2019). A linearized ozone chemistry module (Hsu and Prather, 2009; McLinden et al., 2000) is used to represent stratospheric ozone and its radiative impacts in the stratosphere. Other modifications for model tuning are provided in detail in Xie et al. (2018).

\subsection{Experimental design}

Six Atmospheric Model Intercomparison Project (AMIP) types of simulations are conducted. Four 6-year simulations are forced by prescribed, seasonally varying climatological present-day sea surface temperatures (SSTs) and sea ice extent, recycled yearly (Stone et al., 2018): two with the default deterministic ZM scheme but having 72 and 30 vertical levels (referred to as EAMv1 and EAMv1-30L, respectively) and the other two with the stochastic deep convection scheme (referred to as STOCH and STOCH-30L). The simulations with 30 vertical levels are conducted to facilitate the comparison with Wang et al. (2016), in which the vertical resolution of CAM5 is 30 levels (see Sect. 3.3). To explore the responses of precipitation and its extremes to climate warming, similar to EAMv1 and STOCH runs, two 3-year simulations in a warmer climate are conducted, in which a composite SST warming pattern derived from the Coupled Model Intercomparison Project Phase 3 (CMIP3) coupled models (referred to as EAMv1-4K and STOCH-4K, respectively) is imposed for the boundary condition of the atmosphere. Following Webb et al. (2017), it is a normalized multi-model mean of the sea surface temperature response pattern from 13 
Table 1. List of simulations.

\begin{tabular}{lrrl}
\hline Simulation & Years & Vertical levels & Description \\
\hline EAMv1 & 6 & 72 & $\begin{array}{l}\text { Standard EAMv1 with the default deterministic ZM deep con- } \\
\text { vection scheme for simulating the current climate }\end{array}$ \\
\hline STOCH & 6 & 72 & $\begin{array}{l}\text { Same as EAMv1, but coupling the PC stochastic deep convec- } \\
\text { tion scheme with the deterministic ZM deep convection scheme }\end{array}$ \\
\hline EAMv1-30L & 6 & 30 & $\begin{array}{l}\text { Same as EAMv1, but using a vertical resolution configuration } \\
\text { of 30 layers }\end{array}$ \\
\hline STOCH-30L & 6 & 30 & $\begin{array}{l}\text { Same as STOCH, but using a vertical resolution configuration } \\
\text { of 30 layers }\end{array}$ \\
\hline EAMv1-4K & 3 & 72 & Same as EAMv1, but for simulating a warmer world \\
\hline STOCH-4K & 3 & 72 & Same as STOCH, but for simulating a warmer world \\
\hline
\end{tabular}

a Atmosphere-only simulations using fully prognostic atmosphere and land models with prescribed, seasonally varying climatological present-day sea surface temperatures (SSTs) and sea ice extent, recycled yearly.

${ }^{\mathrm{b}}$ For simulating a warmer world, the atmosphere-only simulations are subjected to a composite SST warming pattern derived from the Coupled Model Intercomparison Project Phase 3 (CMIP3) coupled models.

CMIP3 atmosphere-ocean general circulation models, representing the change in SST between years 0-20 and 140-160, the time of $\mathrm{CO}_{2}$ quadrupling in the $1 \%$ runs. Before calculating the multi-model ensemble mean, the SST response of each model was divided by its global mean and multiplied by $4 \mathrm{~K}$. This guarantees that the pattern information from all models is weighted equally and that the global mean SST forcing is $+4 \mathrm{~K}$ warming. The first year in all simulations is discarded as a spin-up. Information for all experiments is summarized in Table 1.

\subsection{Evaluation data}

For model evaluation, the following datasets are used: the Clouds and the Earth's Radiant Energy System Energy Balanced and Filled (CERES-EBAF) (Loeb et al., 2009) for evaluation of shortwave and longwave cloud radiative forcing; the European Centre for Medium-Range Weather Forecasts Interim Reanalysis (ERAI) (Simmons et al., 2007) for sea level pressure, zonal wind, relative humidity, specific humidity and temperature; the European Remote Sensing Satellite Scatterometer (ERS) (Bentamy et al., 1999) for surface wind stress; and the Willmott-Matsuura (Willmott) (Willmott and Matsuura, 1995) data for land surface air temperature.

The rainfall mean state is evaluated against the Global Precipitation Climatology Project (GPCP) monthly product (version 2.1) at a resolution of $2.5^{\circ}$ (Adler et al., 2003; Huffman et al., 2009), while a daily estimate of GPCP version 1.2 at $1^{\circ}$ horizontal resolution (GPCP 1DD) (Huffman et al., 2001, 2012) is used for the evaluation of precipitation amount distribution. In addition to GPCP, the Xie-Arkin pentad observations at $2.5^{\circ}$ resolution (Xie and Arkin, 1996) and the Tropical Rainfall Measuring Mission 3B42 version 7 (TRMM) daily observations at a resolution of $0.25^{\circ}$ over $\left(50^{\circ} \mathrm{S}, 50^{\circ} \mathrm{N}\right)$ (Huffman et al., 2007) are applied to evaluate the precipitation variance. The TRMM data are also used in the PDF of rainfall intensity and the rainfall amount distribution. To estimate the uncertainty in the PDF of precipitation intensity in observations, additional daily rainfall products are used. These include TAPEER v1.5, GSMaP-NRT-gauge v6.0, PERSIANN CDR v1, CMORPH v1.0 CRT from the Frequent Rainfall Observation on GridS (FROGS) database (Roca et al., 2019) and Global Precipitation Measurement (GPM) IMERG v06b (Huffman et al., 2017). For the rainfall duration evaluation, the TRMM 3B42 v7 3-hourly data are used. To make the comparison consistent between observations and model simulations, the model data with the same output frequency as that in the corresponding observations and/or reanalysis data are used, and all observations and/or reanalysis data are regridded to the same $1^{\circ}$ lat-long grids as EAMv1. The US Department of Energy Atmospheric Radiation Measurement (ARM) multiyear observations for daily precipitation and dilute convective available potential energy (CAPE) over the Southern Great Plains (SGP) site for the time period of 2004-2018 (Xie et al., 2004) and the Green Ocean Amazon (GOAmazon) field campaign (Martin et al., 2016) site for 2014-2015 (Tang et al., 2016) are used to evaluate the simulated CAPE vs. precipitation relationship.

\section{Results}

\subsection{Intraseasonal and synoptic variability}

The simulated variability of precipitation is an important aspect of model performance. Here we focus on intraseasonal and synoptic-scale variability. The intraseasonal variability associated with the Madden-Julian oscillation (MJO) is problematic in many GCMs (Jiang et al., 2015; Zhang and 
(a) Xie-Arkin

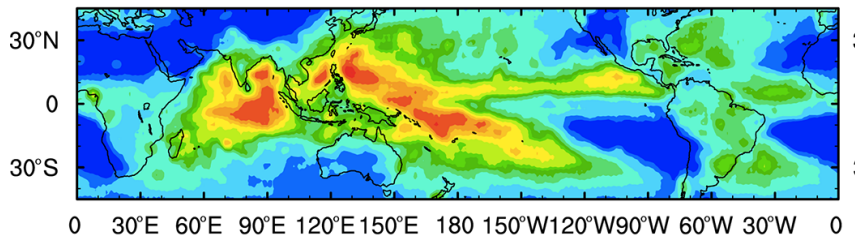

(c) EAMv1

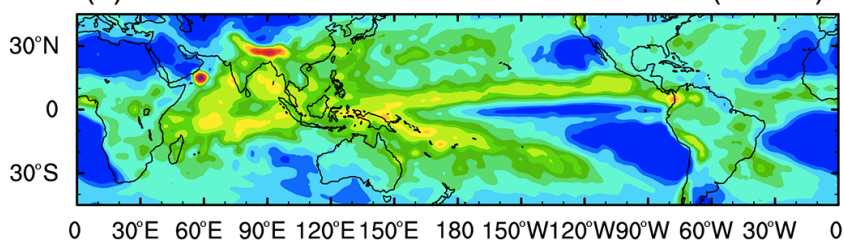

(b) TRMM

$30^{\circ} \mathrm{N}$

$30^{\circ} \mathrm{S}$

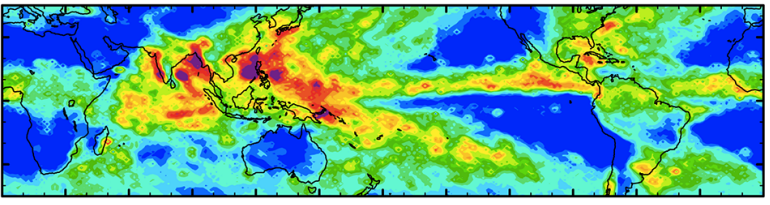

$030^{\circ} \mathrm{E} \quad 60^{\circ} \mathrm{E} 90^{\circ} \mathrm{E} 120^{\circ} \mathrm{E} 150^{\circ} \mathrm{E} 180150^{\circ} \mathrm{W} 120^{\circ} \mathrm{W} 90^{\circ} \mathrm{W} 60^{\circ} \mathrm{W} 30^{\circ} \mathrm{W} \quad 0$

(d) STOCH

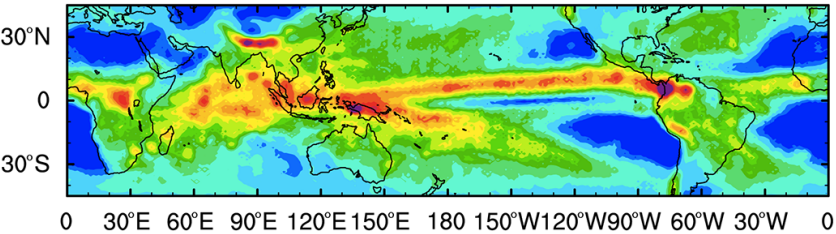

Figure 1. Spatial distributions of the 20-80d variance of rainfall from (a) the Xie-Arkin observations, (b) TRMM, (c) EAMv1 and (d) STOCH (units: $\mathrm{mm}^{2} \mathrm{~d}^{-2}$ ).

$\mathrm{Mu}, 2005 \mathrm{a})$. Figure 1 shows the tropical distribution of the $20-80 \mathrm{~d}$ intraseasonal variance for the total precipitation in observations and simulations. The variance is obtained with a Lanczos band-pass filter at each grid point. Both XieArkin and TRMM observations show large variance in the Indian Ocean and western Pacific as well as in the ITCZ and the South Pacific Convergence Zone (SPCZ). The intraseasonal variance in EAMv1 is much weaker, as in many other GCMs. Similar to the results in Wang et al. (2016), the STOCH run with the stochastic deep convection scheme has significantly enhanced intraseasonal variance in these regions, making it much more comparable to observations, although there is excessive precipitation variance over central Africa, the Himalayas, the Maritime Continent and the region near the Colombian coast. Compared with the EAMv1 run, the STOCH run has more small-scale noise in the spatial structure of the precipitation variability.

Besides the intraseasonal variance, the synoptic variance (2-9 d Lanczos band-pass-filtered rainfall anomalies) is also investigated (Fig. 2). The synoptic-scale variance corresponds to weather activities. In Fig. 2 only TRMM observations are shown to evaluate simulations because the XieArkin observations are pentad data. In TRMM, the geographical distribution of the synoptic variance is similar to that of the intraseasonal variance, but with larger amplitudes because synoptic-scale activities contain much more energy than intraseasonal disturbances. Similar to the intraseasonal variance, the synoptic variance in the EAMv1 run is also much weaker than that in observations. The synoptic-scale variance in the STOCH run is about twice as strong as in EAMv1 although it is still underestimated compared to TRMM observations. Over regions where the overestimated intraseasonal precipitation variance emerges, the STOCH run has excessive synoptic precipitation variance as well. This re- sult is consistent with Goswami et al. (2017), who reported enhanced intraseasonal and synoptic variability of precipitation in the National Centers for Environmental Predictions (NCEP) Climate Forecast System version 2 (CFSv2) using a stochastic multicloud model parameterization.

\subsection{Rainfall frequency, intensity, amount and duration}

Wang et al. (2016) showed that the most significant improvement with the use of the stochastic deep convection scheme in CAM5 was in the simulated PDF of rainfall intensity over the tropics, which became very close to TRMM observations. Since there are many modifications in model configuration and physics parameterizations from CAM5 to EAMv1 (Rasch et al., 2019), such as a finer vertical resolution, an updated microphysics parameterization (MG2), and the use of CLUBB in place of separate shallow convection and planetary boundary layer turbulence parameterizations, it is not clear whether a similar degree of improvement in precipitation intensity PDF can be achieved with a similar stochastic convection scheme. Using an equal-interval rainfall intensity bin of $0.5 \mathrm{~mm} \mathrm{~d}^{-1}$ from 0 to $200 \mathrm{~mm} \mathrm{~d}^{-1}$, Fig. 3 shows the frequencies of the total precipitation intensity over the tropics $\left(20^{\circ} \mathrm{S}-20^{\circ} \mathrm{N}\right)$ from observations, EAMv1 and STOCH. Also shown are the PDFs of large-scale and convective precipitation intensity. The observational uncertainty is larger for intense precipitation than for light precipitation (Fig. 3a), which is consistent with findings in Roca (2019). The GPCP precipitation intensity distribution (the gray curve that even falls below the EAMv1 curve in Fig. 3a) has the lowest frequency for precipitation intensity greater than $30 \mathrm{~mm} \mathrm{~d}^{-1}$. The GPCP product is known to have underestimated precipitation intensities (Kooperman et al., 2016). Despite the uncertainties in observations, the simulated frequencies in 

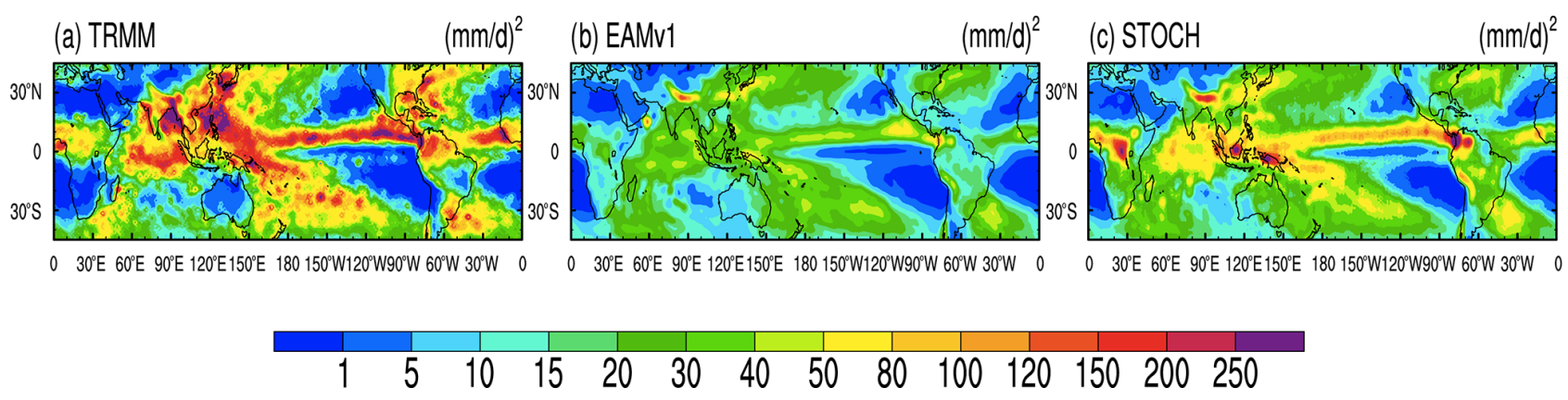

Figure 2. Spatial distributions of the synoptic variance of rainfall from (a) TRMM, (b) EAMv1 and (c) STOCH (units: $\mathrm{mm}^{2} \mathrm{~d}^{-2}$ ).

\section{(a) Total Precipitation}

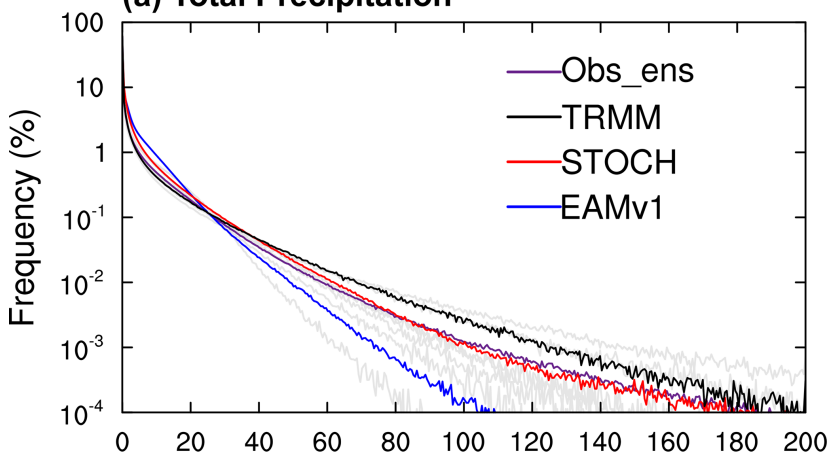

(b) Convective and Large-scale Precipitation

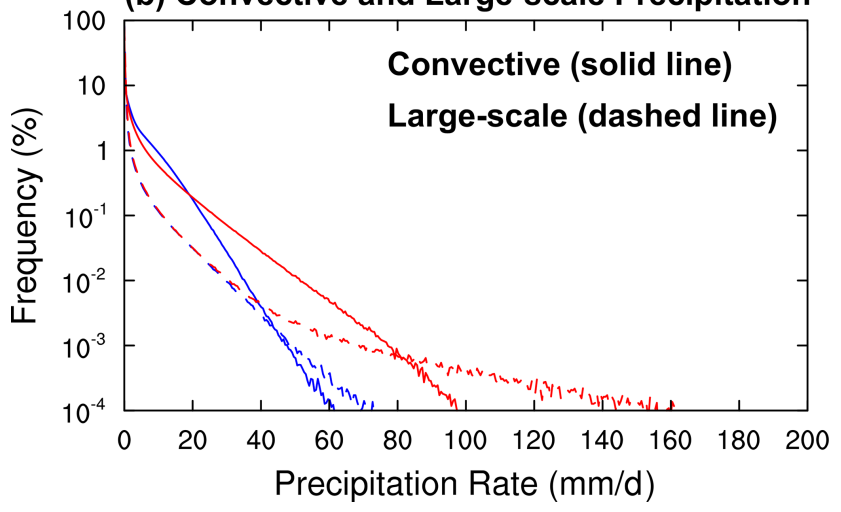

Figure 3. Frequency distributions of (a) total (solid line), (b) convective (solid line) and large-scale (dashed line) precipitation intensity over the tropics $\left(20^{\circ} \mathrm{S}, 20^{\circ} \mathrm{N}\right)$ for EAMv1 (blue) and STOCH (red), respectively. For total precipitation, the TRMM observations (black) and the ensemble mean of multiple observations (Obs_ens, purple), with each observation represented by a gray line, are included for evaluation.

STOCH are more consistent with those in the ensemble mean of all observations than those in the default EAMv1. The stochastic convection parameterization in the STOCH run greatly mitigates the bias of "too much light rain and too little heavy rain", showing a decrease in the frequency of rainfall intensity between 1 and $10 \mathrm{~mm} \mathrm{~d}^{-1}$ and an increase in the frequency of rainfall intensity larger than $20 \mathrm{~mm} \mathrm{~d}^{-1}$ compared to the EAMv1 run. Especially for light rain, the frequencies in STOCH fall in the observational range, while those in EAMv1 do not. A recent study finds that the decreased frequency of light rain has a profound impact on simulated aerosol loading in the atmosphere (Wang et al., 2021a). Xie et al. (2019) indicated that the "too much light rain" in EAMv1 was a result of overly frequent convection. Consistent with this notion, Fig. $3 b$ shows that the reduction of light rain frequency is entirely from convective precipitation. On the other hand, the increase in intense precipitation frequency is from both convective and large-scale precipitation.

To understand why the use of a stochastic convection scheme decreases the frequency of light rain and increases the frequency of heavy rain, we conducted an additional simulation. In the simulation, the setup is identical to the STOCH run except that the $\mathrm{ZM}$ scheme is called a second time at each time step, with input (temperature, moisture, etc.) identical to that for the stochastic scheme. However, the output is used for diagnostic purposes only and does not participate in model integration. It is found that (figure not shown) two factors contribute to the decreased frequency of light rain and increased frequency of heavy rain. First, for a given ensemble mean convective mass flux (from the ZM scheme) the probability for cloud generation following the Poisson distribution for a realization in the stochastic scheme can produce more intense precipitation than obtained by the ZM scheme. Second, the probability distribution results in less frequent convection in general. This allows the buildup of atmospheric instability (also see Fig. 9 below in Sect. 3.3), which also leads to heavier convective rainfall (even with the ZM scheme alone without considering the stochastic part) and more large-scale condensation. However, we note that the increase in the frequency of rainfall intensity ranges from 60 to $140 \mathrm{~mm} \mathrm{~d}^{-1}$ in the STOCH run, which is not as much as that in Wang et al. (2016) for CAM5. This will be elucidated through sensitivity experiments in the next subsection.

The frequencies of total precipitation intensity over selected regions also show a qualitatively similar degree of improvement. Figure 4 shows six regions during their convectively active seasons: Amazonia, the tropical western Pacific, and India for June-September; the Maritime Continent and 
Amazon

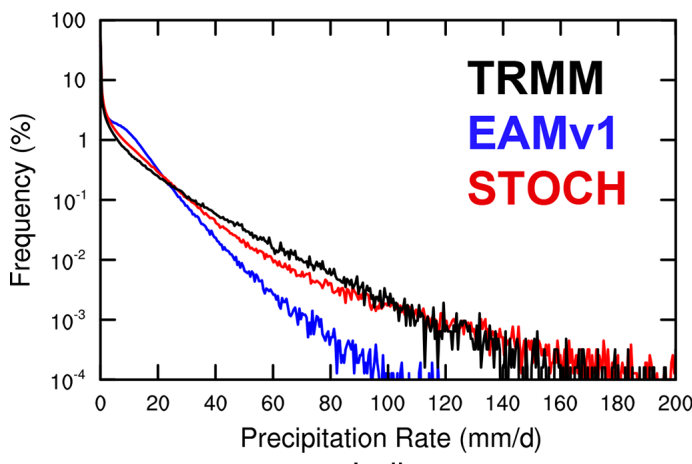

India
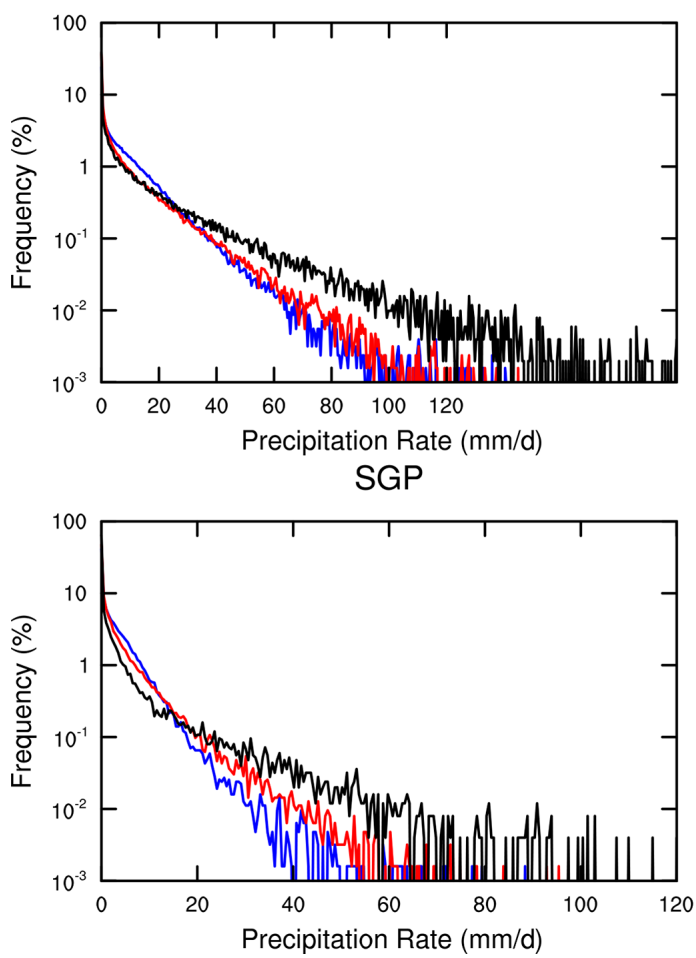

TWP

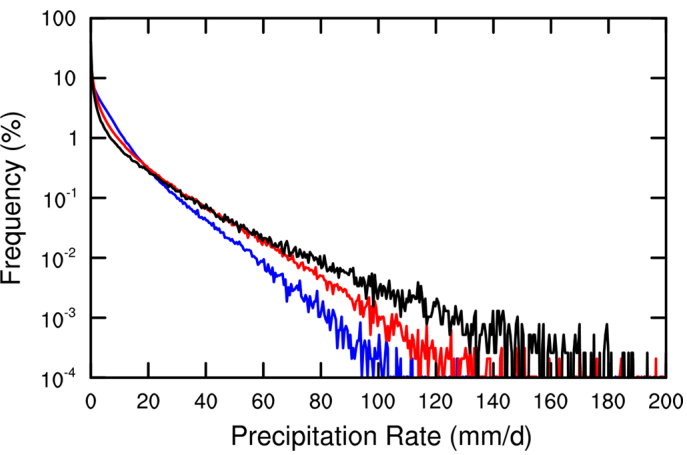

$\mathrm{MC}$
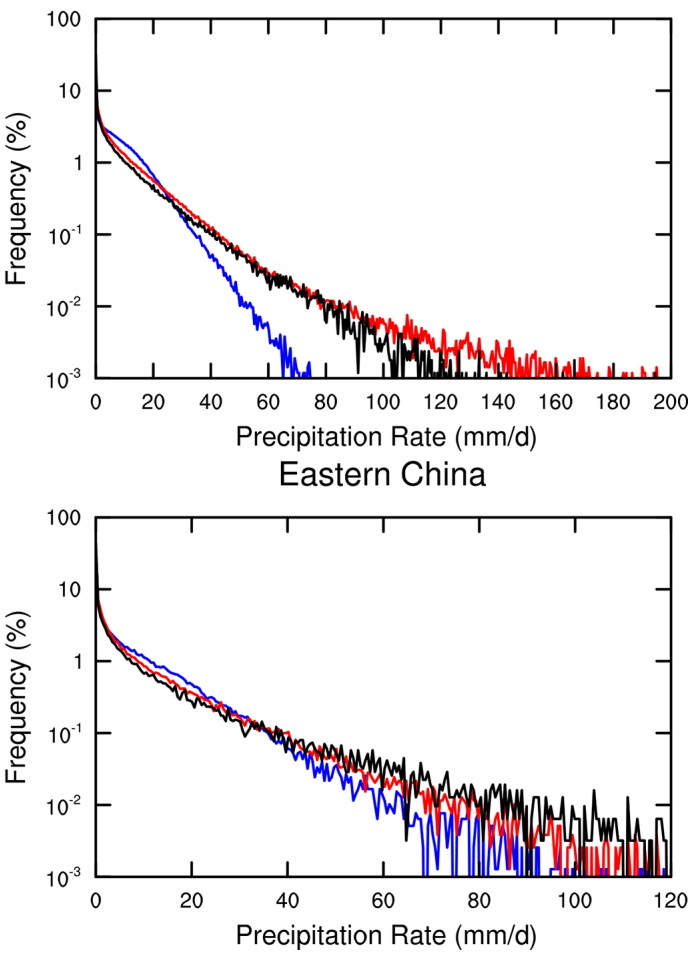

Figure 4. Frequency distributions of total precipitation intensity over the Amazon $\left(20^{\circ} \mathrm{S}-5^{\circ} \mathrm{N}, 40-80^{\circ} \mathrm{W}\right)$, the tropical western Pacific (TWP) $\left(0-15^{\circ} \mathrm{N}, 130-170^{\circ} \mathrm{E}\right)$, India $\left(14-26.5^{\circ} \mathrm{N}, 74.5-94^{\circ} \mathrm{E}\right.$; for June-September), the Maritime Continent $(\mathrm{MC})\left(10^{\circ} \mathrm{S}-10^{\circ} \mathrm{N}, 90-\right.$ $\left.160^{\circ} \mathrm{E}\right)$, the Southern Great Plains (SGP) $\left(37-42^{\circ} \mathrm{N}, 90-110^{\circ} \mathrm{W}\right.$; for May-August) and eastern China $\left(25-35^{\circ} \mathrm{N}, 100-120^{\circ} \mathrm{E}\right.$; for JuneAugust) for TRMM (black), EAMv1 (blue) and STOCH (red).

SGP for May-August; and eastern China for June-August in TRMM, EAMv1 and STOCH, respectively. In all tropical regions, the EAMv1 simulation overestimates the occurrence frequency for precipitation intensities less than $20 \mathrm{~mm} \mathrm{~d}^{-1}$ and underestimates it for precipitation intensities greater than $20 \mathrm{~mm} \mathrm{~d}^{-1}$, similar to the distribution for the entire tropics. In STOCH, the performance in the PDF over Amazonia and the Maritime Continent is better than the PDF over the entire tropics. Although the biases of "too much light rain" over India and the tropical western Pacific are alleviated by the stochastic deep convection scheme, the bias of "too little heavy rain" remains, particularly over India where large-scale monsoonal dynamics regulate heavy convective rain (Wang et al., 2018). For the two midlatitude convection regions (SGP and eastern China), although there is also noticeable improvement across the precipitation intensity spectrum, it is less significant compared to other regions, possibly because convection in midlatitude land regions is not as prevalent as in the tropics.

Figure 5 shows the geographical distributions of precipitation frequency for all precipitation, precipitation intensities less than $20 \mathrm{~mm} \mathrm{~d}^{-1}$ and precipitation intensities more than $20 \mathrm{~mm} \mathrm{~d}^{-1}$ over the tropics in observations and simulations (days with precipitation intensity less than $1 \mathrm{~mm} \mathrm{~d}^{-1}$ are con- 

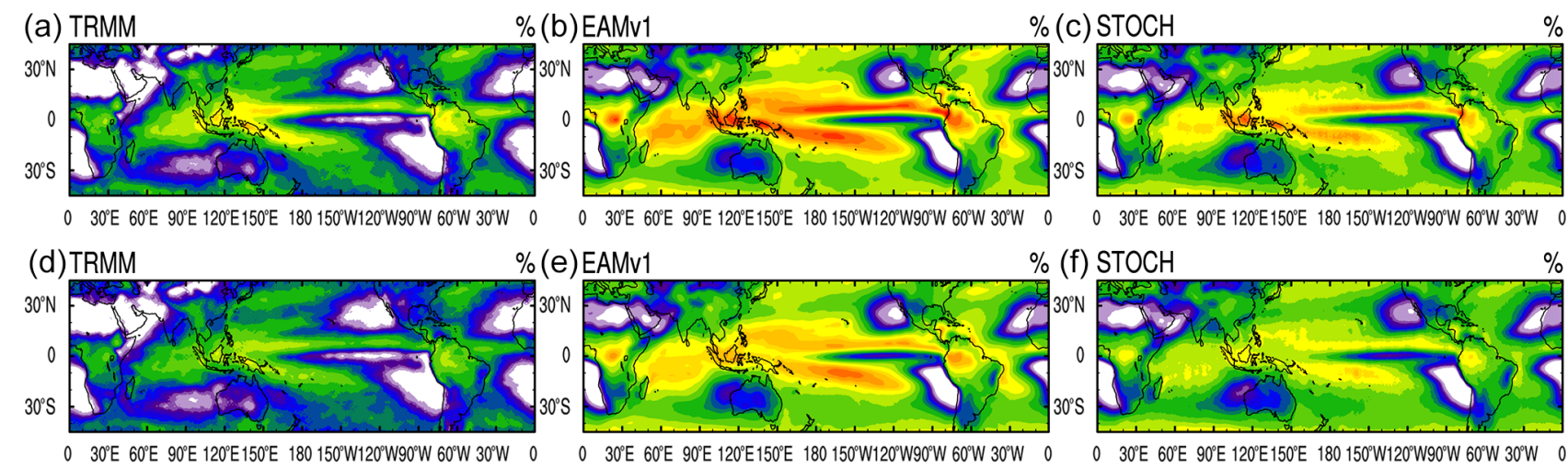

$\%(\mathrm{e})$ EAMv1

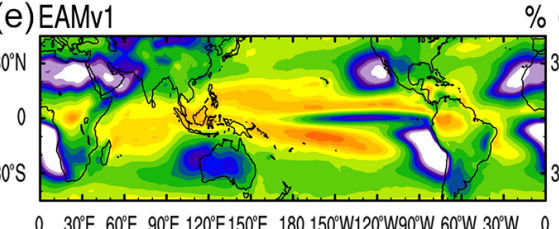

$\%$ (f) STOCH

$030^{\circ} \mathrm{E} 60^{\circ} \mathrm{E} \quad 90^{\circ} \mathrm{E} 120^{\circ} \mathrm{E} 150^{\circ} \mathrm{E} \quad 180150^{\circ} \mathrm{W} 120^{\circ} \mathrm{W} 90^{\circ} \mathrm{W} 60^{\circ} \mathrm{W} 30^{\circ} \mathrm{W} \quad 0$

$030^{\circ} \mathrm{E} 60^{\circ} \mathrm{E} 90^{\circ} \mathrm{E} 120^{\circ} \mathrm{E} 150^{\circ} \mathrm{E} 180150^{\circ} \mathrm{W} 120^{\circ} \mathrm{W} 90^{\circ} \mathrm{W} 60^{\circ} \mathrm{W} 30^{\circ} \mathrm{W}$
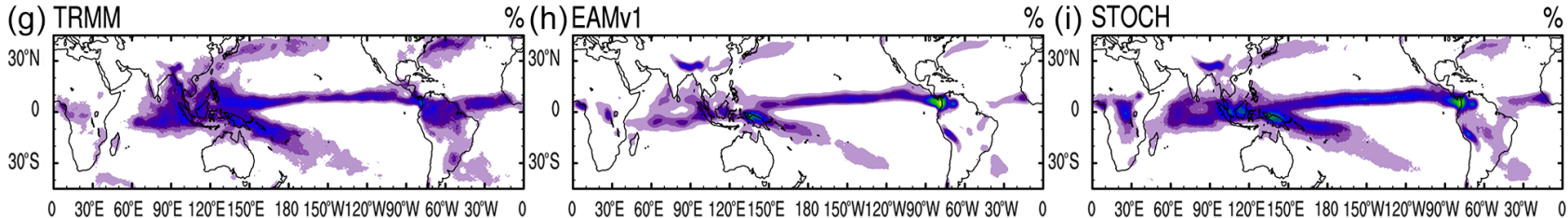

$030^{\circ} \mathrm{E} 60^{\circ} \mathrm{E} 90^{\circ} \mathrm{E} 120^{\circ} \mathrm{E} 150^{\circ} \mathrm{E} \quad 180150^{\circ} \mathrm{W} 120^{\circ} \mathrm{W} 90^{\circ} \mathrm{W} 60^{\circ} \mathrm{W} 30^{\circ} \mathrm{W} \quad 0$

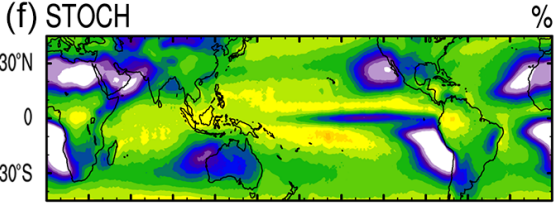

$030^{\circ} \mathrm{E} 60^{\circ} \mathrm{E} 90^{\circ} \mathrm{E} 120^{\circ} \mathrm{E} 150^{\circ} \mathrm{E} 180150^{\circ} \mathrm{W} 120^{\circ} \mathrm{W} 90^{\circ} \mathrm{W} 60^{\circ} \mathrm{W} 30^{\circ} \mathrm{W} \quad 0$

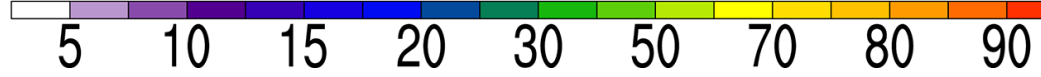

Figure 5. Spatial distributions of the frequencies of total rainfall intensity larger than (a-c) $1 \mathrm{~mm} \mathrm{~d}^{-1}$, (d-f) between 1 and $20 \mathrm{~mm} \mathrm{~d} \mathrm{~d}^{-1}$, and (g-i) larger than $20 \mathrm{~mm} \mathrm{~d}^{-1}$ for TRMM, EAMv1 and STOCH, respectively.

sidered non-precipitating and thus excluded). In TRMM, the occurrence frequency of rainy days ranges from $30 \%$ to $70 \%$, with the most frequent rain along the ITCZ, the SPCZ and in the Indian Ocean, where the EAMv1 run has a frequency as high as $80 \%-90 \%$, with up to $30 \%$ positive biases. In contrast, the $\mathrm{STOCH}$ run reduces the frequency to $50 \%-70 \%$, although it is still overestimated. When the total precipitation is broken down into precipitation rates less than $20 \mathrm{~mm} \mathrm{~d}^{-1}$ and precipitation rates above $20 \mathrm{~mm} \mathrm{~d}^{-1}$, in both observations and simulations the geographical distribution of the rainy days is dominated by days with precipitation intensity less than $20 \mathrm{~mm} \mathrm{~d}^{-1}$. In comparison with observations, again, the STOCH run reduces the positive bias of the frequency of precipitation intensity less than $20 \mathrm{~mm} \mathrm{~d}^{-1}$ in the EAMv1 run by up to $20 \%$. For precipitation intensities greater than $20 \mathrm{~mm} \mathrm{~d}^{-1}$, the EAMv1 run underestimates their frequency compared to the TRMM observations. On the other hand, the frequency of occurrence in the STOCH run is comparable to the TRMM observations.

Another metric for the precipitation PDF is the contribution of precipitation within a given intensity bin to the total precipitation amount. It combines the information on precipitation frequency distribution and precipitation intensity. While drizzle occurs much more frequently than more intense rain events, it may not contribute much to the total precipitation amount. Following the approach of Kooperman et al. $(2016,2018)$, we divide the precipitation rate ranging from 0.1 to $1000 \mathrm{~mm} \mathrm{~d}^{-1}$ into equal bin intervals on a logarithmic scale, with a bin width of $\Delta \ln (R)=\Delta R / R=0.1$.
If the frequency of rainfall rates falling into the $i$ th bin is denoted $f_{i}$, then $f_{i}=n_{i} / N_{\mathrm{t}}$, where $N_{\mathrm{t}}$ is the total number of days, then $n_{i}$ is the number of days with rainfall rates falling into the $i$ th bin. The mean precipitation rate in the $i$ th bin is then

$R_{i}=\frac{1}{n_{i}} \sum_{j=1}^{n_{i}} r_{j}$

where $r_{j}$ is an individual precipitation rate within the $i$ th bin. Thus, the contribution to the total precipitation amount from the $i$ th bin per unit bin width is given by

$P_{i}=\frac{f_{i} R_{i}}{\Delta \ln (R)}=\frac{1}{\Delta \ln (R)} \frac{1}{N_{\mathrm{t}}} \sum_{j=1}^{n_{i}} r_{j}$.

$P_{i}$ has units of millimeters per day $\left(\mathrm{mm} \mathrm{d}^{-1}\right)$. The total precipitation amount is then given by

$P=\sum_{i} P_{i} \Delta \ln (R)=\sum_{i} f_{i} R_{i}$

Accordingly, the amount distributions for total $\left(P^{\mathrm{T}}\right)$, convective $\left(P^{\mathrm{C}}\right)$ and large-scale $\left(P^{\mathrm{L}}\right)$ rainfall are given by the fol- 


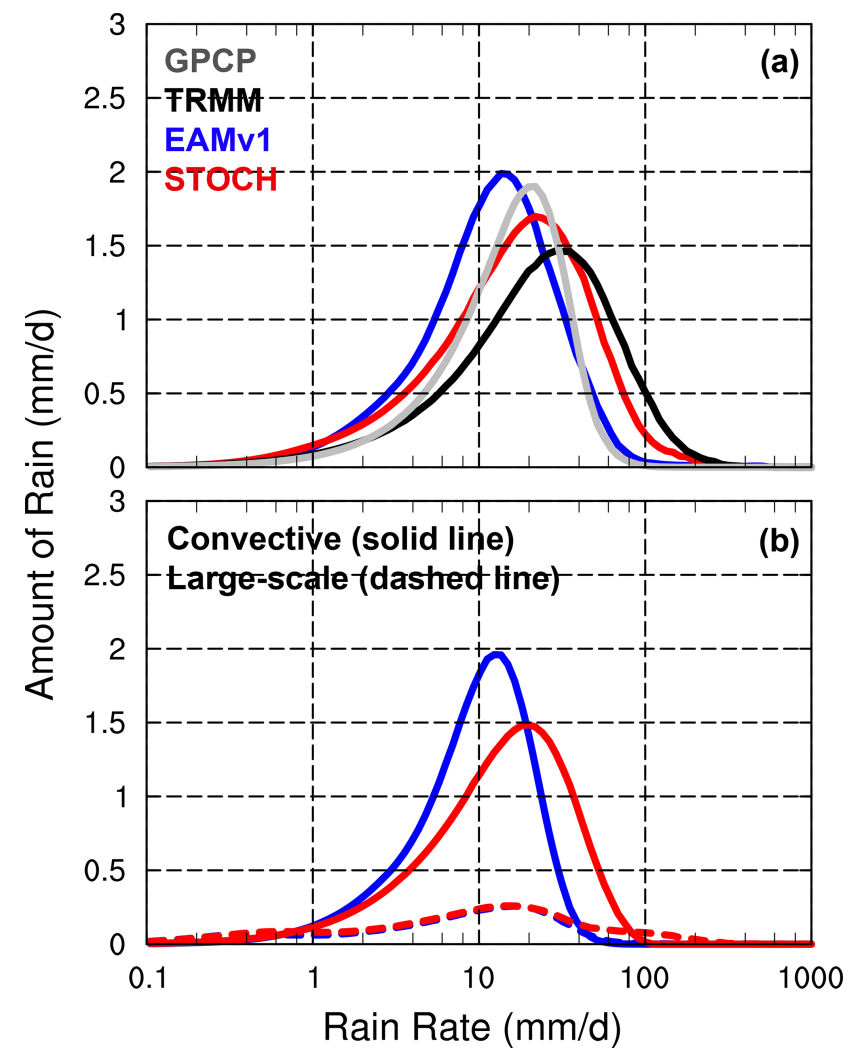

Figure 6. Annual mean rainfall amount distributions of (a) total precipitation (solid line) over the tropics $\left(20^{\circ} \mathrm{S}, 20^{\circ} \mathrm{N}\right)$ for GPCP 1DD (gray), TRMM (black), EAMv1 (blue) and STOCH (red). Individual distributions of (b) convective (solid line) and large-scale (dashed line) precipitation in EAMv1 (blue) and STOCH (red) are also shown. The rainfall intensity on the $x$ axis is on a logarithmic scale with bin intervals of $\Delta \ln (R)=\Delta R / R=0.1$.

lowing.

$$
\begin{aligned}
P_{i}^{\mathrm{T}} & =\frac{1}{\Delta \ln (R)} \frac{1}{N_{\mathrm{t}}} \sum_{j=1}^{n_{i}} r_{j}^{\mathrm{T}} \\
P_{i}^{\mathrm{C}} & =\frac{1}{\Delta \ln (R)} \frac{1}{N_{\mathrm{t}}} \sum_{j=1}^{n_{i}} r_{j}^{\mathrm{C}} \\
P_{i}^{\mathrm{L}} & =\frac{1}{\Delta \ln (R)} \frac{1}{N_{\mathrm{t}}} \sum_{j=1}^{n_{i}} r_{j}^{\mathrm{L}}
\end{aligned}
$$

Here, $r^{\mathrm{T}}, r^{\mathrm{C}}$ and $r^{\mathrm{L}}$ are the total, convective and large-scale rain rates.

Figure $6 \mathrm{a}$ shows the contribution to the total rainfall amount from each rainfall rate on a logarithmic scale for GPCP 1DD, TRMM and the two simulations over the tropics. The TRMM observations have larger contributions from intense rainfall rates than GPCP 1DD, with a peak contribution rainfall rate of $28 \mathrm{~mm} \mathrm{~d}^{-1}$, which is higher than the value of $22 \mathrm{~mm} \mathrm{~d}^{-1}$ in GPCP 1DD. The EAMv1 run produces a much smaller peak contribution rainfall rate $\left(15 \mathrm{~mm} \mathrm{~d}^{-1}\right)$ than the two observations, while the STOCH run simulates it realistically $\left(23 \mathrm{~mm} \mathrm{~d}^{-1}\right)$ as falling between the two ob-

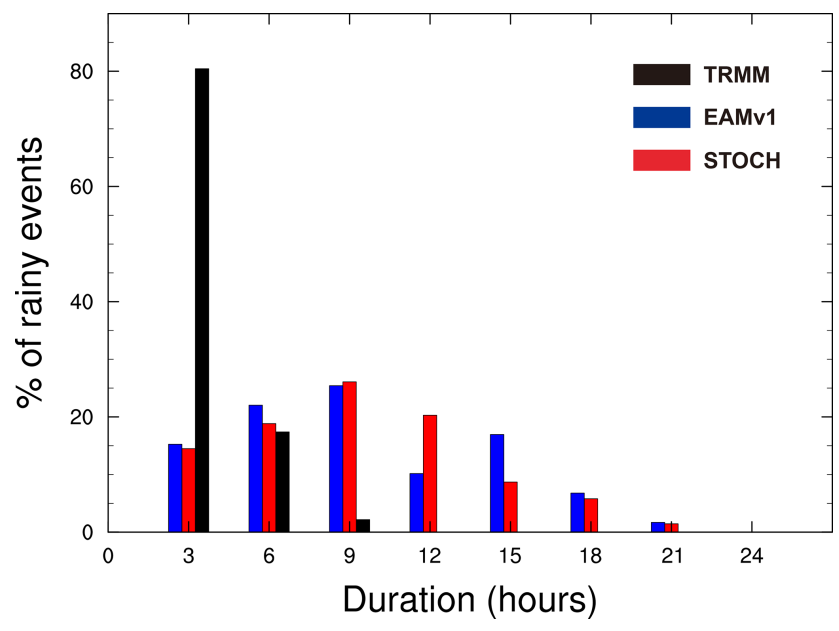

Figure 7. Histogram of the percentage frequency of total rainy events as a function of their duration using 3-hourly data (conditional probability of rainfall given rainfall from previous times) from TRMM (black), EAMv1 (blue) and STOCH (red) for the threshold rainfall rate of $1 \mathrm{~mm} \mathrm{~d}^{-1}$ over the tropics.

servations. Note that precipitation from intensities less than $1 \mathrm{~mm} \mathrm{~d}^{-1}$ contributes about $0.05 \mathrm{~mm} \mathrm{~d}^{-1}$ or less to the tropical mean total precipitation, thus justifying treating it as non-precipitating in Fig. 5. Figure $6 \mathrm{~b}$ shows the convective and large-scale contributions to the simulated total precipitation from EAMv1 and STOCH, respectively. The large-scale precipitation shows very similar contribution distributions in the two simulations except for the largest rain rates, which make only a small contribution to the total. For the most part, large-scale precipitation is not affected by how convection is treated in the model, with both simulations having a maximum contribution near $22 \mathrm{~mm} \mathrm{~d}^{-1}$. On the other hand, the convective contribution is very different between the two simulations. Similar to the total precipitation, the peak contribution to convective precipitation is at a much smaller rainfall rate in EAMv1 than in STOCH.

Besides precipitation frequency and intensity, another important higher-order statistic of precipitation is the duration of precipitation events; it measures the intermittency of precipitation (Trenberth et al., 2017). Using 3-hourly data, we calculate the duration of rainfall events as a continuous number of hours of precipitation exceeding a threshold value of $1 \mathrm{~mm} \mathrm{~d}^{-1}$. Figure 7 shows the frequency of precipitation events for different durations over the tropics; $80 \%$ of TRMM-observed precipitation events last for $3 \mathrm{~h}$ or less, $18 \%$ last for $6 \mathrm{~h}$ and $2 \%$ last for $9 \mathrm{~h}$. In contrast, both EAMv 1 and STOCH produce very small proportions $(\sim 15 \%)$ of precipitation events that last for $3 \mathrm{~h}$ or less. The frequency of precipitation events lasting $9 \mathrm{~h}$ or longer is extremely overestimated in the model simulations, with some lasting for as long as $21 \mathrm{~h}$. This suggests that convection in the model lacks the observed intermittency (Trenberth et al., 2017), and 
(a) Total Precipitation

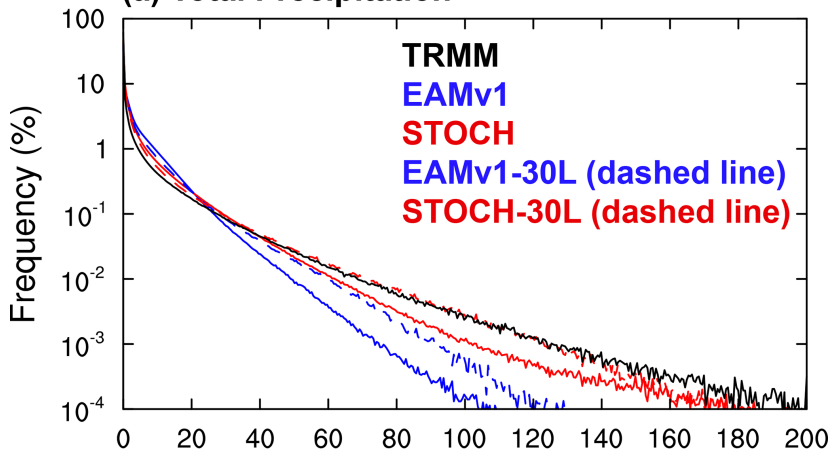

(b) Convective Precipitation

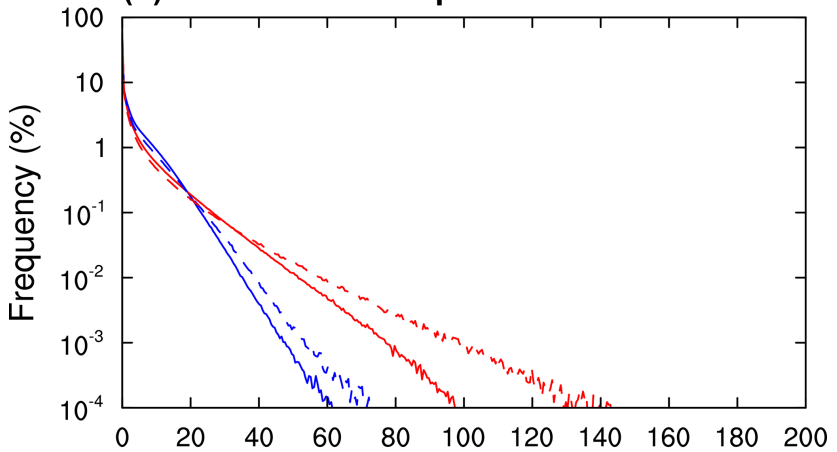

(c) Large-scale Precipitation

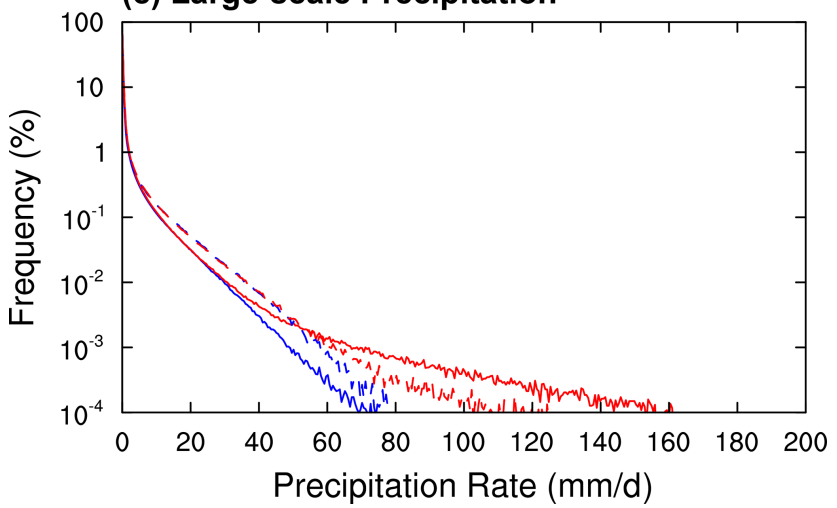

Figure 8. Same as Fig. 3, but including PDFs for EAMv1-30L and STOCH-30L (both dashed lines).

the use of the stochastic convection scheme does not improve this aspect of the simulated convection.

\subsection{Sensitivity of rainfall intensity PDF to vertical resolution}

A significant modification among several changes in EAMv1 from CAM5 is a much finer vertical resolution, increasing from 30 levels in CAM5 to 72 levels in EAMv1. Within the PBL alone EAMv1 has 17 layers compared to 5 layers in CAM5, and the thickness of approximately $20 \mathrm{~m}$ for the lowest model layer in EAMv1 is much thinner than that in CAM5, which is $100 \mathrm{~m}$ (Xie et al., 2018). The increased resolution in the PBL in EAMv1 will likely affect the convec- tion behavior through PBL-convection interactions. In Fig. 3 we show that the precipitation intensity PDF is significantly improved with the introduction of the stochastic convection scheme. However, the improvement was not as striking as that shown in Wang et al. (2016) for CAM5. We suspect that this is primarily due to the enhanced vertical resolution in EAMv1 rather than other changes in model physics parameterizations, tunings or the model dynamic core. To confirm this, EAMv1-30L and STOCH-30L runs with a vertical resolution of 30 layers are conducted and compared with the EAMv1 and STOCH runs with the default 72 vertical layers. As seen in Fig. 8, when switching to a configuration of 30 vertical layers, the performance of the STOCH-30L run is very similar to that in CAM5 (Wang et al., 2016). The frequency distribution of rainfall intensity between 60 and $140 \mathrm{~mm} \mathrm{~d}^{-1}$ almost falls on top of that in TRMM. The PDF of rain intensity in the EAMv1-30L run is also closer to TRMM observations compared to the EAMv1 run (Fig. 8a). For EAMv1, convective and large-scale precipitation becomes more intense in the 30-level configuration. The resolution dependence of large-scale precipitation is consistent with the scale analysis in Rauscher et al. (2016). In their Eq. (2), if the terms are rearranged to solve for vertical velocity $(\omega)$, it gives $\omega \propto \Delta p$, the vertical grid spacing in pressure coordinates. Stronger vertical velocity would lead to more intense precipitation. In STOCH-30L, while the frequency of more intense convective precipitation is increased, the frequency of more intense large-scale precipitation is decreased, probably affected by the moisture depletion from strong convective precipitation (Fig. 8b, c).

The causes of the sensitivity of convective precipitation to vertical resolution are further examined below. In the ZM convection scheme, the amount of convection is linked to dilute CAPE (for convenience we will simply call it CAPE below with the understanding that it refers to dilute CAPE). Thus, in Fig. 9 we present the joint PDF of convective precipitation and CAPE over the tropics in the four simulations. Note that all parameter settings are identical between EAMv1 and EAMv1-30L except the vertical resolution. Both EAMv1 and EAMv1-30L show an approximately linear relationship between CAPE and convective precipitation. The CAPE values are generally smaller in EAMv1-30L than in EAMv1, as can be seen from the frequency of occurrence of both large and medium CAPE values. However, the slope of the maximum occurrence frequency is almost twice as large in EAMv1-30L as in EAMv1 (Fig. 9a, b), giving the higher frequency of larger convective precipitation as seen in Fig. 8. This is because a coarser vertical resolution means stronger vertical mixing, which results in higher precipitation for given CAPE values. For a given precipitation rate that the model produces, there is in general a large range of CAPE values, and the CAPE values in EAMv1 are predominantly larger than in EAMv1-30L as can be seen from the PDF distribution in Fig. 9a and b. Compared to EAMv1, the smaller CAPE values in EAMv1-30L are caused by higher parcel 
(a) EAMv1

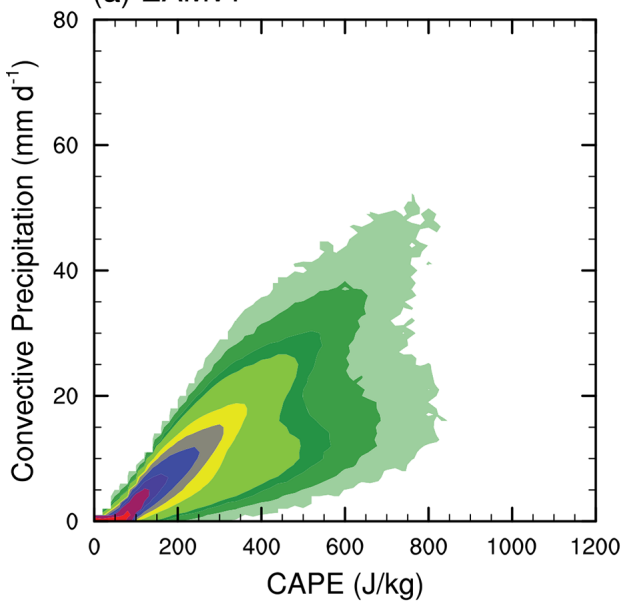

(c) $\mathrm{STOCH}$

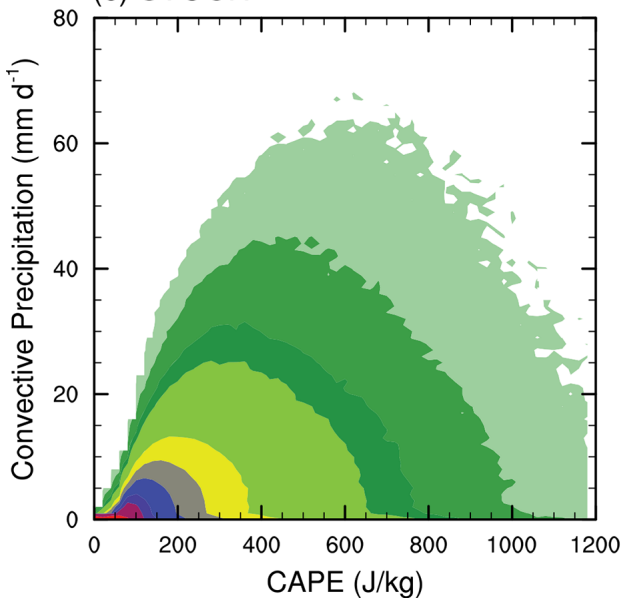

(b) EAMv1-30L

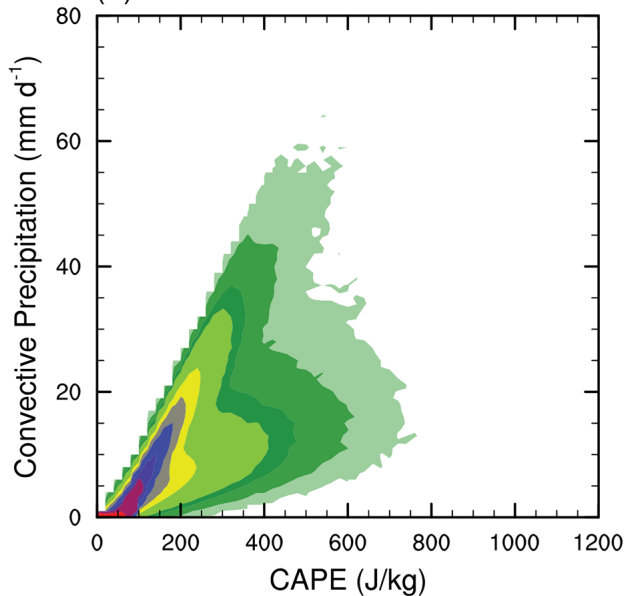

(d) STOCH-30L

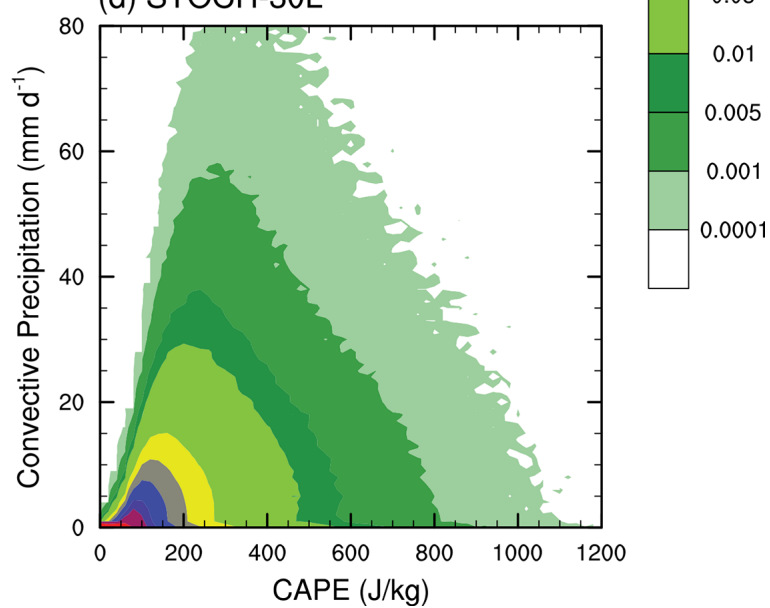

Figure 9. Joint PDFs of CAPE versus convective precipitation over the tropics $\left(20^{\circ} \mathrm{S}, 20^{\circ} \mathrm{N}\right)$ from (a) EAMv1, (b) EAMv1-30L, (c) STOCH and (d) STOCH-30L.

launching levels due to thicker model layers near the surface, where the most unstable air is often found (figure not shown). There is also a bifurcation for medium to large CAPE values. This is likely related to atmospheric moisture conditions in the atmosphere: for the same CAPE values there is less precipitation when the atmosphere is dry and vice versa. With the introduction of the stochastic deep convection scheme, there are no longer approximately linear relations between CAPE and convective precipitation (Fig. 9c, d) in spite of the fact that the CAPE-based closure is still used to determine the cloud-base mass flux (the ensemble mean). This is surprising; it implies that for a given convectively unstable atmospheric thermodynamic condition, the use of the stochastic scheme often inhibits the triggering of convection, thereby allowing for the buildup of CAPE for (the less frequently occurring) stronger convection. Similar to EAMv1, smaller (larger) CAPE values occur more (less) frequently in STOCH-30L due to higher parcel launching levels. Also, the small and moderate values of CAPE have larger probabilities to precipitate more in STOCH-30L compared to STOCH.

Over the ARM SGP and GOAmazon sites, no linear relationship is seen between the total precipitation and CAPE in observations (Fig. 10). At the SGP site, high CAPE values generally correspond to low precipitation. At the GOAmazon site, high precipitation values correspond to medium values of CAPE, somewhat resembling the STOCH simulation, although the observed CAPE values at the GOAmazon site are much smaller than those in the simulations.

\subsection{Mean state}

So far, we have shown that the introduction of a stochastic convection scheme into the E3SM atmospheric model can significantly improve the simulation of the short-term variability and intensity PDF of precipitation. In climate model development efforts, it is important that an improvement in some aspects of the model does not lead to degradation 
(a) OBS

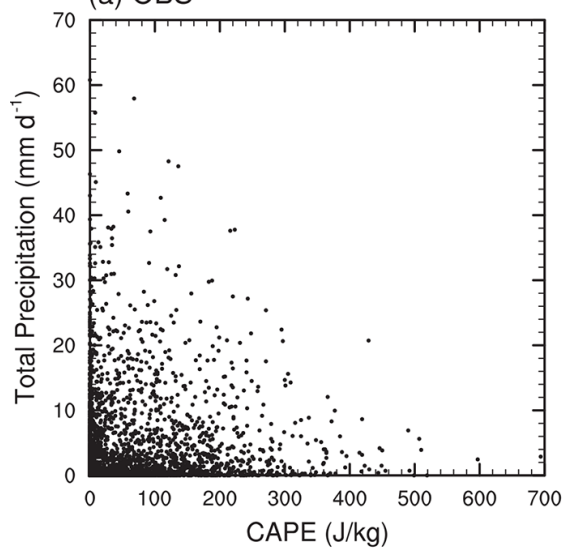

(d) OBS

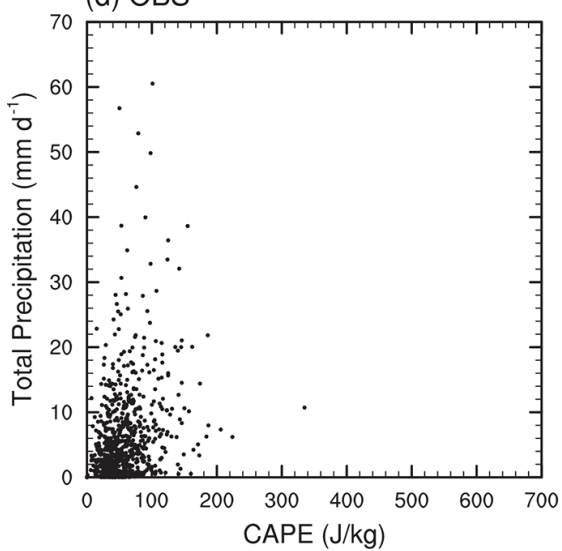

(b) EAMv1

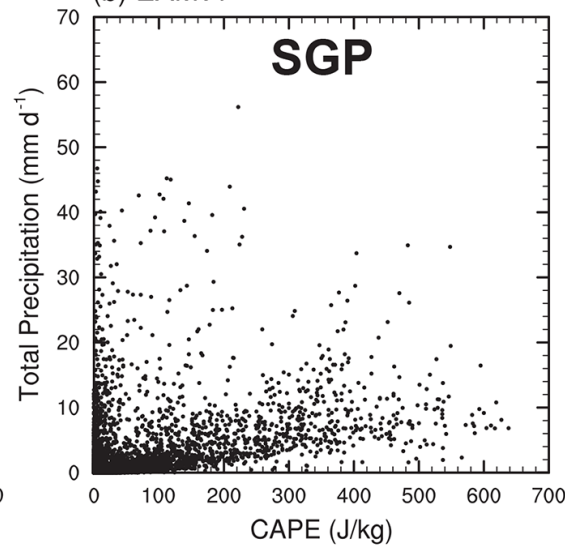

(e) EAMv1

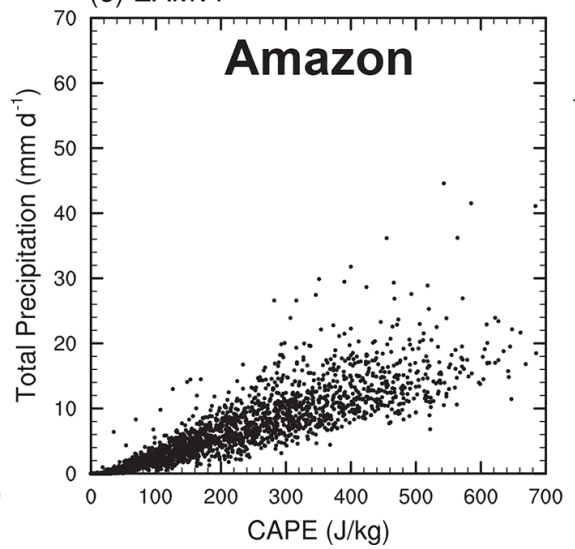

(c) STOCH

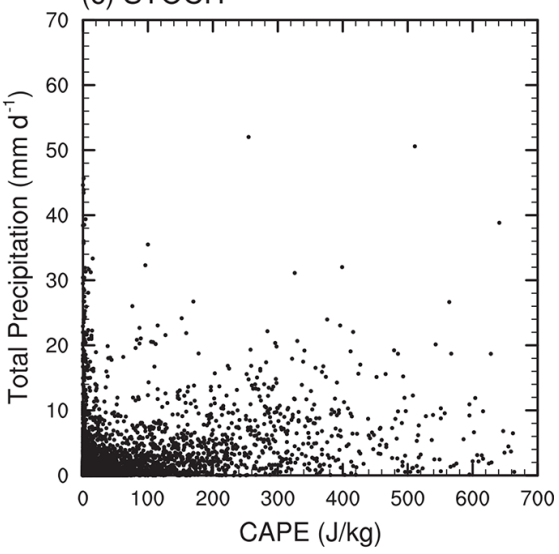

(f) $\mathrm{STOCH}$

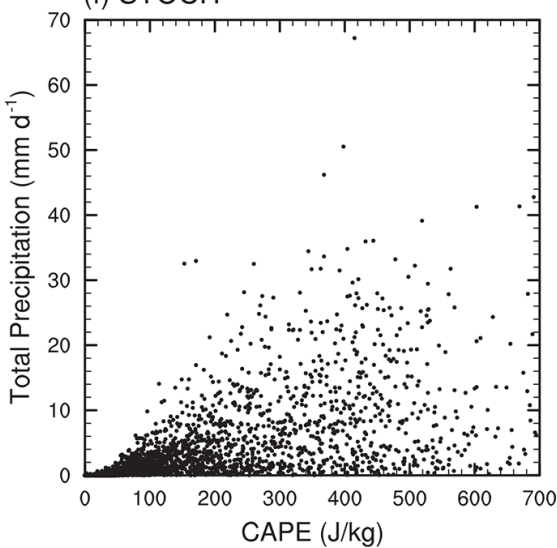

Figure 10. Scatterplots of total precipitation versus CAPE at the ARM (a-c) SGP and (d-f) Amazon sites for (a, d) observations calculated from multiyear sounding data (2014-2015 for the Amazon and 2004-2018 for SGP), (b, e) EAMv1 and (c, f) STOCH.

of other aspects, at least not to outweigh the improvement. Thus, it is imperative that we examine the climate mean fields as well. Figure 11 shows the global distribution of annual mean precipitation in GPCP observations and simulations, as well as the differences in total, convective and large-scale precipitation between the STOCH and EAMv1 runs. Overall, the geographical distributions of precipitation in the two simulations are similar to those in observations, but both overestimate the tropical precipitation (Fig. 11a-c). There is a slight increase in rainfall over the tropical western Pacific, equatorial Indian Ocean and Africa as well as a slight decrease over India and Amazonia in the STOCH simulation (Fig. 11d). Most of these changes are from convective precipitation except over equatorial Africa where the changes are from largescale precipitation (Fig. 11e, f).

The zonal mean of temperature and specific humidity from ERAI and the model biases are shown in Fig. 12. For temperature, EAMv1 produces mostly negative biases in the entire troposphere over the tropics and subtropics and positive biases in the lower troposphere at high latitudes. With the stochastic deep convection scheme used, the temperature changes in STOCH are very minor, increasing slightly from
EAMv1. In the simulation of specific humidity, there are positive biases in the lower troposphere across all latitudes and negative biases above $900 \mathrm{hPa}$ over the tropics and subtropics in EAMv1. In comparison with EAMv1, the negative biases are alleviated, but the positive biases are increased slightly in STOCH.

The overall difference in model performance as measured by the commonly used mean climate metrics between EAMv1 and STOCH runs is summarized in a Taylor diagram (Fig. 13). Most metrics are comparable between the two simulations except precipitation, especially over land where STOCH shows a larger standard deviation than both GPCP and EAMv1. In short, the mean climate does not change much after the incorporation of the stochastic convection scheme in EAMv1. This is practically desirable since one does not need to heavily re-tune the model, a task that is often time-consuming and more of engineering than scientific interest. 
(a) GPCP

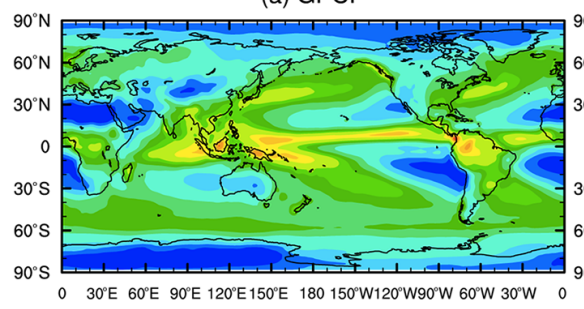

(b) EAMv1

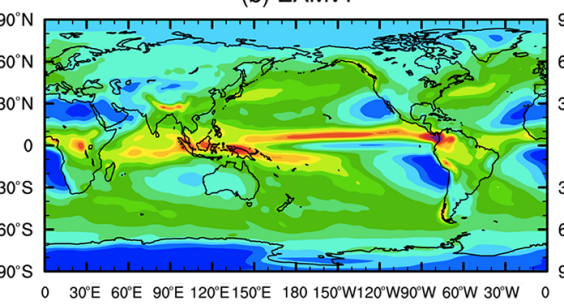

(c) $\mathrm{STOCH}$

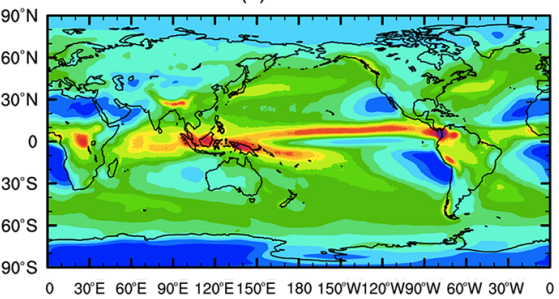

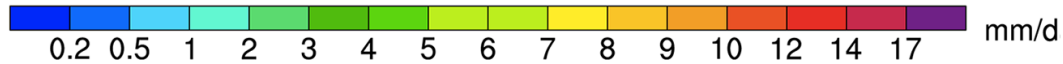

(d) Diff: Total

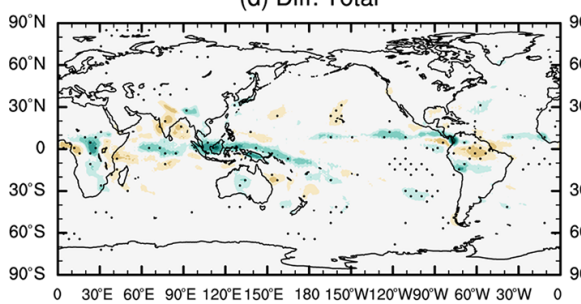

(e) Diff: Conv

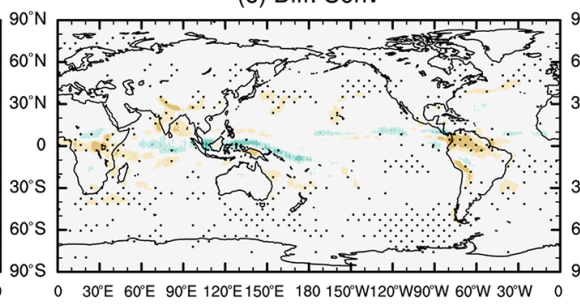

(f) Diff: Large-scale

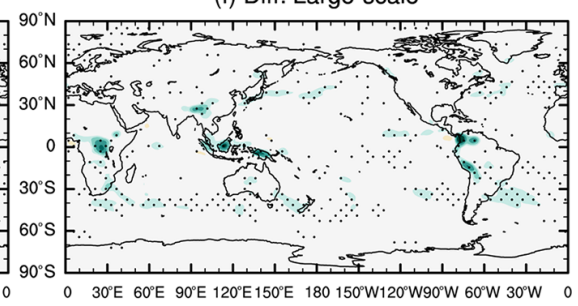

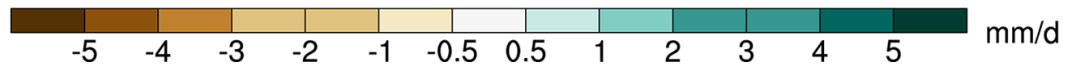

Figure 11. Global distributions of total precipitation for (a) GPCP, (b) EAMv1 and (c) STOCH, as well as the differences of (d) total, (e) convective and (f) large-scale precipitation between STOCH and EAMv1. Differences with a confidence level greater than $95 \%$ in (d-f) are stippled.
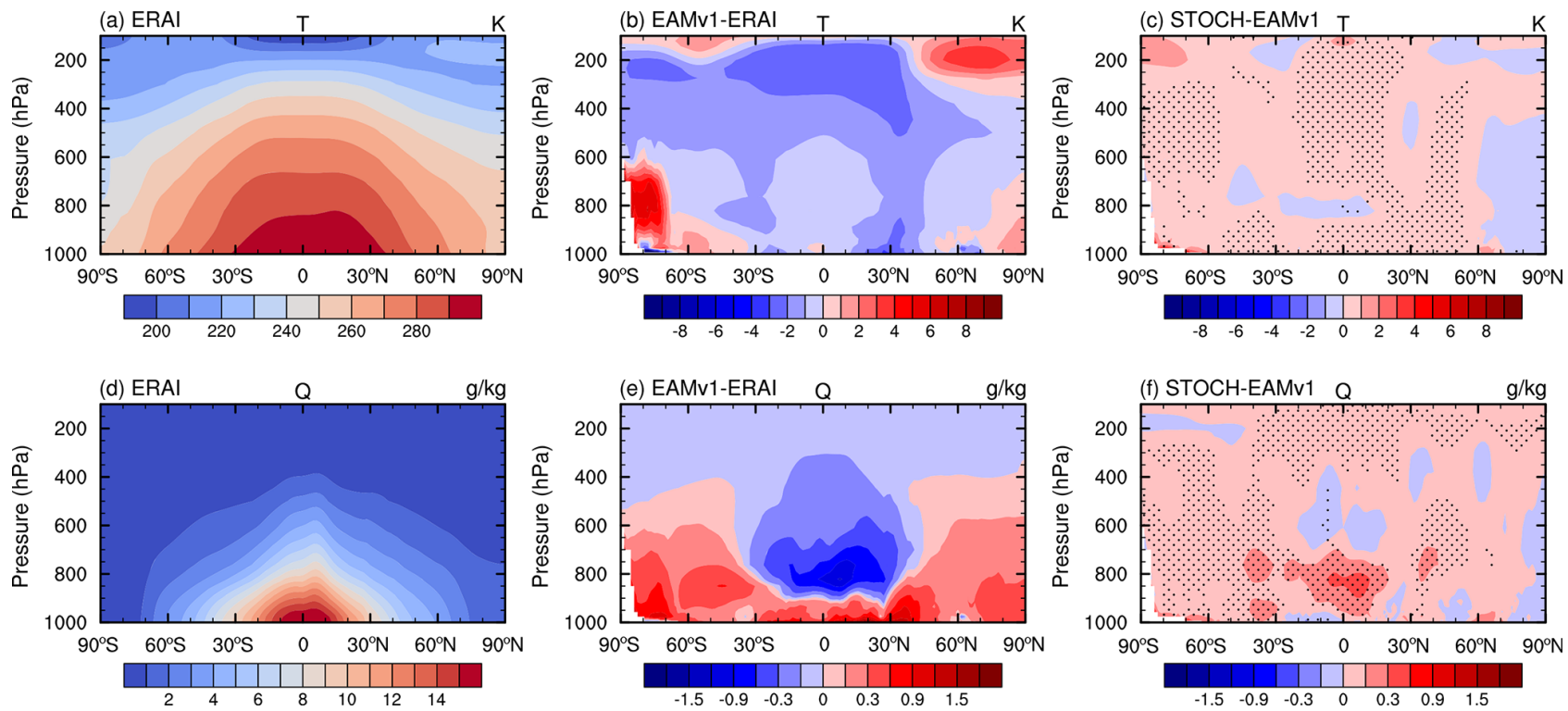

Figure 12. Annual and zonal mean cross sections of (a-c) temperature and (d-f) specific humidity for (a, d) ERAI and differences for (b, e) EAMv1-ERAI and (c, f) STOCH-EAMv1. Differences with a confidence level greater than $95 \%$ between STOCH and EAMv1 are stippled.

\subsection{Response to climate warming}

Another aspect of interest concerns the model's response to climate change. It is well-known that the estimated climate sensitivity for future climate projections is sensitive to changes in model physics parameterizations (Golaz et al., 2019). With the stochastic deep convection parameterization, it is necessary to check if the response of precipitation and associated extremes to climate warming differs. As seen in Fig. 14, relative to the current climate simulations, the 


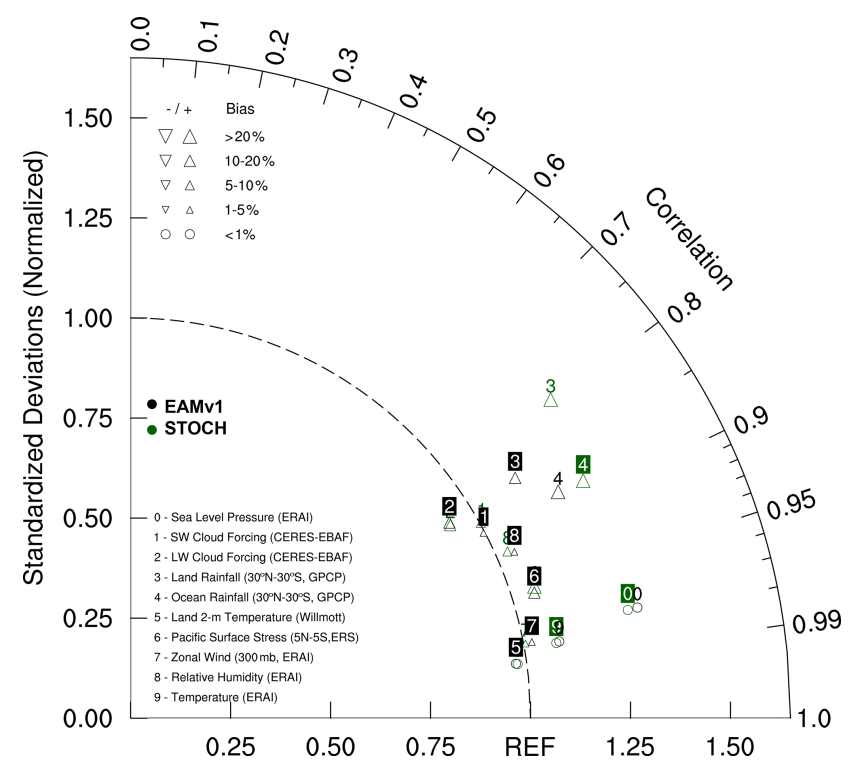

Figure 13. Taylor diagram with metrics for STOCH compared with EAMv1.

geographical patterns and magnitudes of annual mean precipitation changes normalized by the global mean surface air warming $\left(\Delta T_{\mathrm{sa}}\right)$ in the $+4 \mathrm{~K}$ SST warming simulations (i.e., $\left(P_{+4 \mathrm{~K}}-P\right) / P / \Delta T_{\mathrm{sa}}$, units: $\left.\% \mathrm{~K}^{-1}\right)$ with and without the stochastic deep convection scheme are very similar, with both showing maximum increases over the ITCZ, the western Pacific and the Indian Ocean. Pendergrass et al. (2019) found that the response of extreme precipitation to warming follows a nonlinear relation:

$$
\frac{\mathrm{d} r_{x}}{\mathrm{~d} T_{\mathrm{sa}}}=a T_{\mathrm{sa}}
$$

or

$r_{x}=\frac{1}{2} a T_{\mathrm{sa}}^{2}+b$,

where $r_{x}$ is a rainfall extreme index (here using R95p, the total rainfall from the days with daily rainfall intensity exceeding 95th percentile of the daily precipitation distribution), $T_{\mathrm{sa}}$ is the global mean surface air temperature in a warmer world, and $a$ is the slope of $\mathrm{d} r_{x} / \mathrm{d} T_{\mathrm{sa}}$ versus $T_{\mathrm{sa}}$ measuring the strength of the nonlinear response of extreme rainfall to warming. At each grid point, $\mathrm{d} r_{x} \approx \Delta r_{x}$ is equal to R95p in a warmer world minus that under the current climate and normalized by the global mean surface air warming $\left(\mathrm{d} T_{\mathrm{sa}} \approx \Delta T_{\mathrm{sa}}\right)$. With $T_{\mathrm{sa}}$ in the $+4 \mathrm{~K} \mathrm{SST}$ warming simulations and the calculated $\mathrm{d} r_{x} / \mathrm{d} T_{\text {sa }}$, the global distributions of the slope, $a$ (units: $\% \mathrm{~K}^{-2}$ ), with and without the stochastic deep convection scheme are displayed in Fig. 14c and d. Although the stochastic deep convection parameterization introduces stochasticity into convection and significantly improves the underestimated frequency of intense precipitation under the current climate (Wang et al., 2017), it does not lead to a different nonlinear response of precipitation extremes in a warmer world. The resemblance of the coefficient $a$ between the two simulations results from the similar response of the fractional change in $r_{x}$ to global warming (Fig. 14e, f). Increasing circulation strength as the climate warms is considered to be the main driver for the nonlinear relationship between tropical precipitation extremes and global mean surface air temperature (Pendergrass et al., 2019), and it is possible that the circulation changes with and without the stochastic deep convection scheme are similar. Relative to their respective current climate states, the responses of the EAMv1$4 \mathrm{~K}$ and STOCH-4K runs show similar geographical distributions with comparable maximum nonlinearity over the tropical Pacific and Atlantic and the Indian Ocean, which bears some resemblance to that in Pendergrass et al. (2019).

\section{Summary}

In this study, we implemented the stochastic deep convection scheme (Plant and Craig, 2008; Wang et al., 2016) into the DOE EAMv1 and investigated its impact on the simulation of precipitation. Several improvements are observed with the use of the stochastic convection scheme: (1) the weak intraseasonal and synoptic-scale variabilities in EAMv1 are enhanced to levels much closer to those in observations; (2) the "too much light rain and too little heavy rain" bias over the tropics is significantly alleviated due to less frequent occurrence of drizzling convection and more frequent occurrence of intense large-scale and convective precipitation, contributing to enhanced heavy rain; and (3) the simulated peak precipitation rates (the amount mode) in the precipitation amount distribution, which contribute the most to the total amount of precipitation, are larger and in better agreement with those in TRMM and GPCP observations.

While the improvement in the simulated PDF of rainfall intensity is significant, it is less than what we had expected based on our earlier work with the NCAR CAM5 (Wang et al., 2016). Since there are many changes from CAM5 to EAMv1, including vertical resolution, model dynamic core and physics parameterizations, it is not clear which changes are related to the difference in the improvement of the simulated rainfall PDF. Two sensitivity tests were performed to elucidate this, both with a coarser-vertical-resolution configuration of 30 layers (i.e., EAMv1-30L and STOCH-30L) as in CAM5. The STOCH-30L run successfully reproduces the frequency distribution of rainfall intensity found by Wang et al. (2016), with an increased frequency of convective precipitation intensities between 60 and $140 \mathrm{~mm} \mathrm{~d}^{-1}$. This increase is explained by the fact that small and moderate values of CAPE generate more convective precipitation from the altered relation between them compared to the 72-level configuration due to fewer model layers in the 30-level resolution. Since vertical velocity in general increases with the vertical grid spacing, the increase in large-scale precipitation 
(a) EAMv1-4K

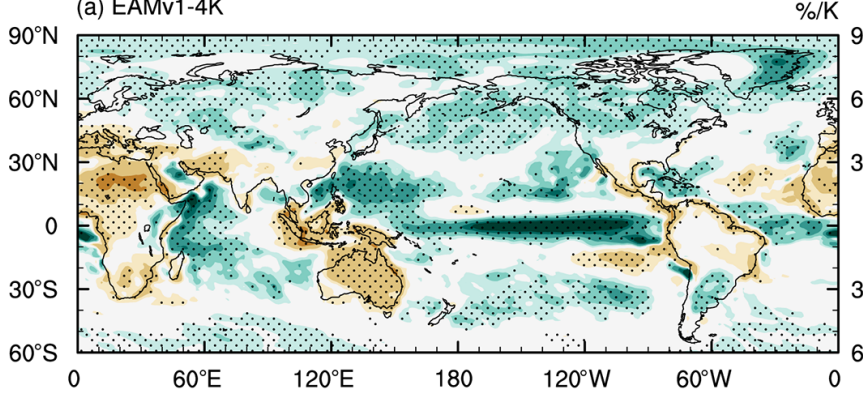

(b) STOCH-4K

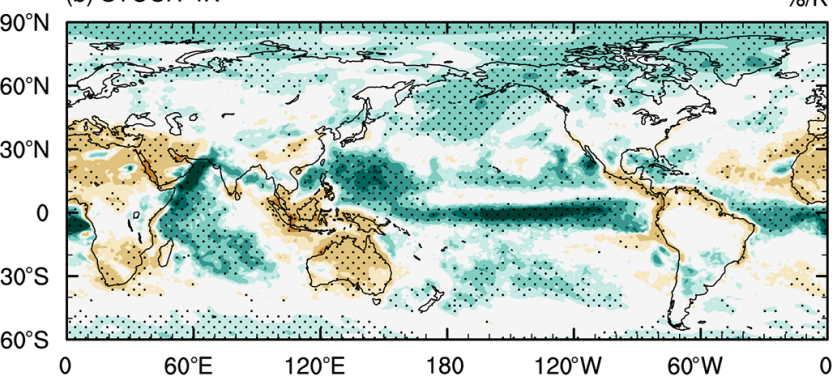

(c) EAMv1-4K

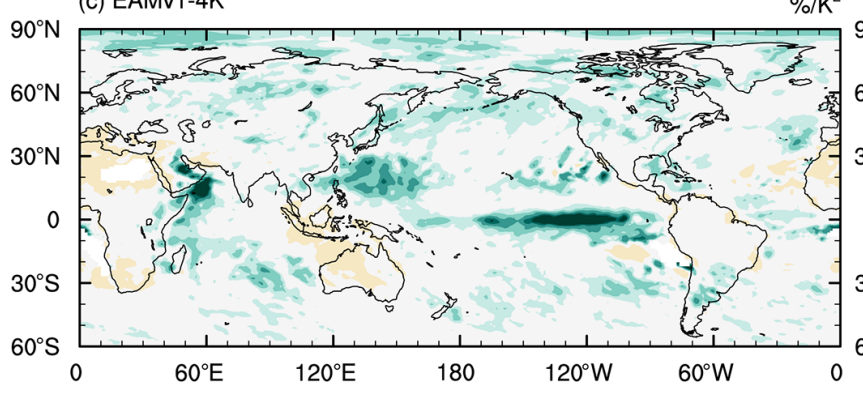

(d) STOCH-4K

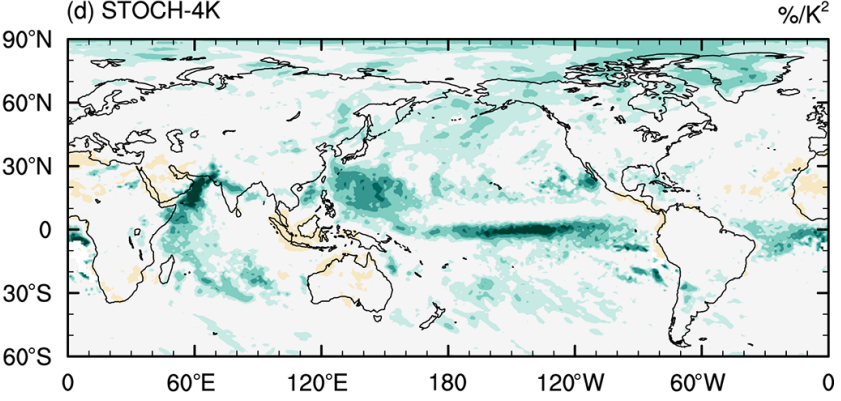

\begin{tabular}{|ll|l|l|l|l|l|l|l|l|l|}
\hline & & & & & & & & & & \\
\hline-0.6 & -0.3 & -0.1 & 0 & 0.1 & 0.3 & 0.6
\end{tabular}

(e) EAMv1-4K

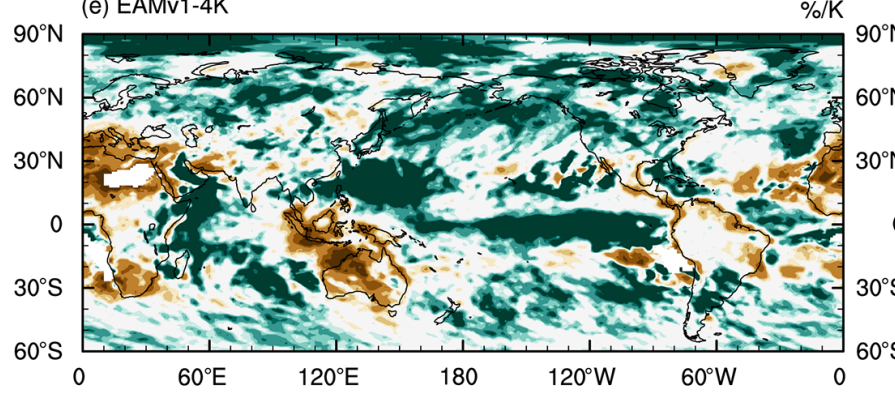

(f) $\mathrm{STOCH}-4 \mathrm{~K}$

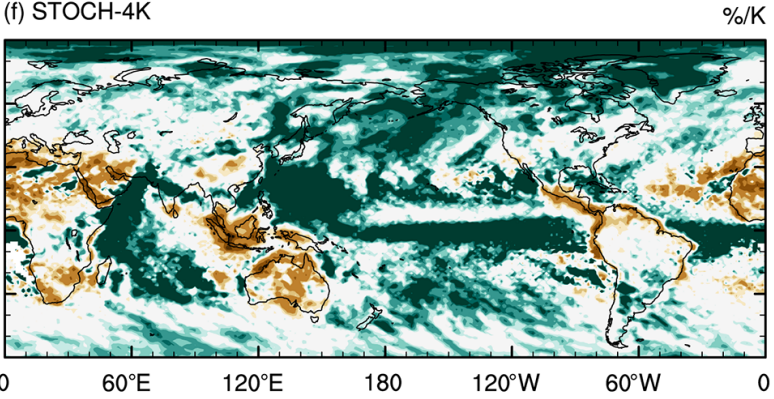

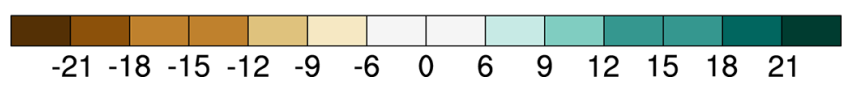

Figure 14. Geographical distributions of the responses of $(\mathbf{a}, \mathbf{b})$ annual mean precipitation, (c, d) the coefficient $a$ and (e, f) the fractional change in precipitation extremes (R95p) to climate warming from $+4 \mathrm{~K}$ experiments. Differences with a confidence level greater than $95 \%$ are stippled.

also contributes to the increased frequency of total precipitation intensities in the 30-level configuration.

For any changes in model physics parameterizations that improve some aspects of the model performance, it is important that other aspects are not degraded. It is known in the climate modeling community that improved intraseasonal variability is often accompanied by a degradation of the mean state (e.g., Kim et al., 2011; Klingaman and Demott, 2020). We showed that the mean states in tropospheric temperature, moisture and precipitation are not much different with or without the use of the stochastic convection scheme, and neither are the responses of mean precipitation and precipitation extremes to climate warming. This is encouraging and desirable for model development efforts. However, we note that for higher horizontal resolutions (Caldwell et al., 2019) or a regionally refined mesh version of EAMv1 (Tang et al., 2019), spatial averaging of the input fields of the stochastic scheme would be needed to make use of convective quasiequilibrium over a larger domain. This could be challenging 
for computational efficiency, and it requires further research in the future.

Code and data availability. The E3SMv1 source code can be downloaded from the E3SM official website at https://e $3 \mathrm{sm}$. org/ (last access: 6 October 2019). The stochastic convection code is accessible from an open repository, Zenodo (https://doi.org/10.5281/zenodo.4543261, Wang et al., 2021b). The GPCP 1DD data are available from NASA GSFC RSD (https: //psl.noaa.gov/data/gridded/data.gpcp.html, last access: 8 November 2015). TRMM and GPM data are available from https:// gpm.nasa.gov/data/directory (last access: 27 March 2020). The availability of daily precipitation observations from the FROGS database is described in Roca et al. (2019). The ARM observations over the SGP and GOAmazon sites are available from https: //www.arm.gov/data (last access: 27 January 2021). The EAMv1 simulation output and a mapping file are provided on Zenodo (https://doi.org/10.5281/zenodo.3902998, Wang et al., 2020, and https://doi.org/10.5281/zenodo.4543233, Wang, 2021).

Author contributions. GJZ conceived the idea. YW developed the model code. YW and WL conducted the model simulations. YW performed the analysis. YW and GJZ interpreted the results and wrote the paper. All authors participated in the revision and editing of the paper.

Competing interests. The authors declare that they have no conflict of interest.

Acknowledgements. This research used resources of the National Energy Research Scientific Computing Center, a DOE Office of Science User Facility supported by the Office of Science of the US DOE under contract no. DE-AC02-05CH11231. The authors would like to thank the two anonymous reviewers for their constructive and helpful comments.

Financial support. This work is supported by the National Key Research and Development Program of China (grant no. 2017YFA0604000) and the National Natural Science Foundation of China (grant nos. 41975126 and 41605074). Guang J. Zhang is supported by the Department of Energy, Office of Science, Biological and Environmental Research Program (BER) (award number DE-SC0019373). George C. Craig is supported by subproject A1 of the Transregional Collaborative Research Center SFB/TRR 165 "Waves to Weather" (http://www.wavestoweather.de, last access: 28 May 2020) funded by the German Research Foundation (DFG). Work at LLNL was performed under the auspices of the US DOE by the Lawrence Livermore National Laboratory under contract no. DE-AC52-07NA27344. Shaocheng Xie and Qi Tang are supported by the DOE Energy Exascale Earth System Model (E3SM) project, and Hsi-Yen Ma is funded by the DOE Regional and Global Model Analysis program area (RGMA) and ASR's Cloud-Associated Parameterizations Testbed (CAPT) project.
Review statement. This paper was edited by Richard Neale and reviewed by two anonymous referees.

\section{References}

Adler, R. F., Huffman, G. J., Chang, A., Ferraro, R., Xie, P.P., Janowiak, J., Rudolf, B., Schneider, U., Curtis, S., and Bolvin, D.: The version-2 global precipitation climatology project (GPCP) monthly precipitation analysis (1979-present), J. Hydrometeorol., 4, 1147-1167, 2003.

Bentamy, A., Queffeulou, P., Quilfen, Y., and Katsaros, K.: Ocean surface wind fields estimated from satellite active and passive microwave instruments, IEEE T. Geosci. R., 37, 2469-2486, 1999.

Caldwell, P. M., Mametjanov, A., Tang, Q., Van Roekel, L. P., Golaz, J.-C., Lin, W., Bader, D. C., Keen, N. D., Feng, Y., Jacob, R., Maltrud, M. E., Roberts, A. F., Taylor, M. A., Veneziani, M., Wang, H., Wolfe, J. D., Balaguru, K., Cameron-Smith, P., Dong, L., Klein, S. A., Leung, L. R., Li, H.-Y., Li, Q., Liu, X., Neale, R. B., Pinheiro, M., Qian, Y., Ullrich, P. A., Xie, S., Yang, Y., Zhang, Y., Zhang, K., and Zhou, T.: The DOE E3SM Coupled Model Version 1: Description and Results at High Resolution, J. Adv. Model. Earth Sy., 11, 4095-4146, https://doi.org/10.1029/2019ms001870, 2019.

Cohen, B. G. and Craig, G. C.: Fluctuations in an Equilibrium Convective Ensemble. Part II: Numerical Experiments, J. Atmos. Sci., 63, 2005-2015, https://doi.org/10.1175/JAS3710.1, 2006.

Craig, G. C. and Cohen, B. G.: Fluctuations in an Equilibrium Convective Ensemble. Part I: Theoretical Formulation, J. Atmos. Sci., 63, 1996-2004, https://doi.org/10.1175/JAS3709.1, 2006.

Dai, A.: Precipitation Characteristics in Eighteen Coupled Climate Models, J. Climate, 19, 4605-4630, https://doi.org/10.1175/JCLI3884.1, 2006.

Davies, L., Jakob, C., May, P., Kumar, V. V., and Xie, S.: Relationships between the large-scale atmosphere and the small-scale convective state for Darwin, Australia, J. Geophys. Res.-Atmos., 118, 11534-511545, https://doi.org/10.1002/jgrd.50645, 2013.

Gettelman, A., Morrison, H., Santos, S., Bogenschutz, P., and Caldwell, P.: Advanced two-moment bulk microphysics for global models. Part II: Global model solutions and aerosol-cloud interactions, J. Climate, 28, 1288-1307, 2015.

Golaz, J.-C., Larson, V. E., and Cotton, W. R.: A PDF-based model for boundary layer clouds. Part I: Method and model description, J. Atmos. Sci., 59, 3540-3551, 2002.

Golaz, J.-C., Caldwell, P. M., Van Roekel, L. P., Petersen, M. R., Tang, Q., Wolfe, J. D., Abeshu, G., Anantharaj, V., Asay-Davis, X. S., Bader, D. C., Baldwin, S. A., Bisht, G., Bogenschutz, P. A., Branstetter, M., Brunke, M. A., Brus, S. R., Burrows, S. M., Cameron-Smith, P. J., Donahue, A. S., Deakin, M., Easter, R. C., Evans, K. J., Feng, Y., Flanner, M., Foucar, J. G., Fyke, J. G., Griffin, B. M., Hannay, C., Harrop, B. E., Hoffman, M. J., Hunke, E. C., Jacob, R. L., Jacobsen, D. W., Jeffery, N., Jones, P. W., Keen, N. D., Klein, S. A., Larson, V. E., Leung, L. R., Li, H.-Y., Lin, W., Lipscomb, W. H., Ma, P.-L., Mahajan, S., Maltrud, M. E., Mametjanov, A., McClean, J. L., McCoy, R. B., Neale, R. B., Price, S. F., Qian, Y., Rasch, P. J., Reeves Eyre, J. E. J., Riley, W. J., Ringler, T. D., Roberts, A. F., Roesler, E. L., Salinger, A. G., Shaheen, Z., Shi, X., Singh, B., Tang, J., Taylor, M. A., Thornton, P. E., Turner, A. K., Veneziani, M., Wan, H., Wang, H., Wang, 
S., Williams, D. N., Wolfram, P. J., Worley, P. H., Xie, S., Yang, Y., Yoon, J.-H., Zelinka, M. D., Zender, C. S., Zeng, X., Zhang, C., Zhang, K., Zhang, Y., Zheng, X., Zhou, T., and Zhu, Q.: The DOE E3SM Coupled Model Version 1: Overview and Evaluation at Standard Resolution, J. Adv. Model. Earth Sy., 11, 2089-2129, https://doi.org/10.1029/2018ms001603, 2019.

Goswami, B., Khouider, B., Phani, R., Mukhopadhyay, P., and Majda, A.: Improving synoptic and intraseasonal variability in CFSv2 via stochastic representation of organized convection, Geophys. Res. Lett., 44, 1104-1113, 2017.

Groenemeijer, P. and Craig, G. C.: Ensemble forecasting with a stochastic convective parametrization based on equilibrium statistics, Atmos. Chem. Phys., 12, 4555-4565, https://doi.org/10.5194/acp-12-4555-2012, 2012.

Hsu, J. and Prather, M. J.: Stratospheric variability and tropospheric ozone, J. Geophys. Res.-Atmos., 114, D06102, https://doi.org/10.1029/2008JD010942, 2009.

Huffman, G. J., Adler, R. F., Morrissey, M. M., Bolvin, D. T., Curtis, S., Joyce, R., McGavock, B., and Susskind, J.: lobal precipitation at one-degree daily resolution from multisatellite observations, $\mathrm{J}$. Hydrometeorol., 2, 36-50, 2001.

Huffman, G. J., Bolvin, D. T., Nelkin, E. J., Wolff, D. B., Adler, R. F., Gu, G., Hong, Y., Bowman, K. P., and Stocker, E. F.: The TRMM multisatellite precipitation analysis (TMPA): Quasiglobal, multiyear, combined-sensor precipitation estimates at fine scales, J. Hydrometeorol., 8, 38-55, 2007.

Huffman, G. J., Adler, R. F., Bolvin, D. T., and Gu, G.: Improving the global precipitation record: GPCP Version 2.1, Geophys. Res. Lett., 36, L17808, https://doi.org/10.1029/2009GL040000, 2009.

Huffman, G. J., Bolvin, D., and Adler, R.: GPCP version 1.2 1degree daily (1DD) precipitation data set, World Data Center A, National Climatic Data Center, Asheville, USA, available at ftp:// rsd.gsfc.nasa.gov/pub/1dd-v1.2/ (last access: 8 November 2015), 2012

Huffman, G. J., Bolvin, D. T., and Nelkin, E. J.: Integrated Multisatellite Retrievals for GPM (IMERG) technical documentation, available at: https://pmm.nasa.gov/sites/default/files/document_ files/IMERG_doc.pdf (last access: 8 July 2019), 2017.

Jiang, X., Waliser, D. E., Xavier, P. K., Petch, J., Klingaman, N. P., Woolnough, S. J., Guan, B., Bellon, G., Crueger, T., DeMott, C., Hannay, C., Lin, H., Hu, W., Kim, D., Lappen, C.L., Lu, M.-M., Ma, H.-Y., Miyakawa, T., Ridout, J. A., Schubert, S. D., Scinocca, J., Seo, K.-H., Shindo, E., Song, X., Stan, C., Tseng, W.-L., Wang, W., Wu, T., Wu, X., Wyser, K., Zhang, G. J., and Zhu, H.: Vertical structure and physical processes of the Madden-Julian oscillation: Exploring key model physics in climate simulations, J. Geophys. Res.-Atmos., 120, 4718-4748, https://doi.org/10.1002/2014JD022375, 2015.

Jones, T. R. and Randall, D. A.: Quantifying the limits of convective parameterizations, J. Geophys. Res.-Atmos., 116, D08210, https://doi.org/10.1029/2010jd014913, 2011

Keane, R. J., Craig, G. C., Keil, C., and Zängl, G.: The Plant-Craig Stochastic Convection Scheme in ICON and Its Scale Adaptivity, J. Atmos. Sci., 71, 3404-3415, https://doi.org/10.1175/JASD-13-0331.1, 2014.

Keane, R. J., Plant, R. S., and Tennant, W. J.: Evaluation of the Plant-Craig stochastic convection scheme (v2.0) in the ensemble forecasting system MOGREPS-R $(24 \mathrm{~km})$ based on the Unified Model (v7.3), Geosci. Model Dev., 9, 1921-1935, https://doi.org/10.5194/gmd-9-1921-2016, 2016.

Khouider, B., Biello, J., and Majda, A. J.: A stochastic multicloud model for tropical convection, Commun. Math. Sci., 8, 187-216, 2010.

Kim, D., Sobel, A. H., Maloney, E. D., Frierson, D. M., and Kang, I.-S.: A systematic relationship between intraseasonal variability and mean state bias in AGCM simulations, J. Climate, 24, 55065520, 2011.

Klingaman, N. P. and Demott, C. A.: Mean State Biases and Interannual Variability Affect Perceived Sensitivities of the MaddenJulian Oscillation to Air-Sea Coupling, J. Adv. Model. Earth Sy., 12, e2019MS001799, https://doi.org/10.1029/2019ms001799, 2020.

Kooperman, G. J., Pritchard, M. S., Burt, M. A., Branson, M. D., and Randall, D. A.: Robust effects of cloud superparameterization on simulated daily rainfall intensity statistics across multiple versions of the Community Earth System Model, J. Adv. Model. Earth Sy., 8, 140-165, 2016.

Kooperman, G. J., Pritchard, M. S., O’Brien, T. A., and Timmermans, B. W.: Rainfall From Resolved Rather Than Parameterized Processes Better Represents the Present-Day and Climate Change Response of Moderate Rates in the Community Atmosphere Model, J. Adv. Model. Earth Sy., 10, 971-988, 2018.

Larson, V. E. and Golaz, J.-C.: Using probability density functions to derive consistent closure relationships among higher-order moments, Mon. Weather Rev., 133, 1023-1042, 2005.

Lin, J. W. B. and Neelin, J. D.: Influence of a stochastic moist convective parameterization on tropical climate variability, Geophys. Res. Lett., 27, 3691-3694, 2000.

Lin, J. W.-B. and Neelin, J. D.: Considerations for stochastic convective parameterization, J. Atmos. Sci., 59, 959-975, 2002.

Liu, X., Ma, P.-L., Wang, H., Tilmes, S., Singh, B., Easter, R. C., Ghan, S. J., and Rasch, P. J.: Description and evaluation of a new four-mode version of the Modal Aerosol Module (MAM4) within version 5.3 of the Community Atmosphere Model, Geosci. Model Dev., 9, 505-522, https://doi.org/10.5194/gmd-9505-2016, 2016.

Loeb, N. G., Wielicki, B. A., Doelling, D. R., Smith, G. L., Keyes, D. F., Kato, S., Manalo-Smith, N., and Wong, T.: Toward optimal closure of the Earth's top-of-atmosphere radiation budget, J. Climate, 22, 748-766, 2009.

Martin, S. T., Artaxo, P., Machado, L. A. T., Manzi, A. O., Souza, R. A. F., Schumacher, C., Wang, J., Andreae, M. O., Barbosa, H. M. J., Fan, J., Fisch, G., Goldstein, A. H., Guenther, A., Jimenez, J. L., Pöschl, U., Silva Dias, M. A., Smith, J. N., and Wendisch, M.: Introduction: Observations and Modeling of the Green Ocean Amazon (GoAmazon2014/5), Atmos. Chem. Phys., 16, 47854797, https://doi.org/10.5194/acp-16-4785-2016, 2016.

McLinden, C., Olsen, S., Hannegan, B., Wild, O., Prather, M., and Sundet, J.: Stratospheric ozone in 3-D models: A simple chemistry and the cross-tropopause flux, J. Geophys. Res.-Atmos., 105, 14653-14665, 2000.

Morrison, H. and Gettelman, A.: A New Two-Moment Bulk Stratiform Cloud Microphysics Scheme in the Community Atmosphere Model, Version 3 (CAM3). Part I: Description and Numerical Tests, J. Climate, 21, 3642-3659, https://doi.org/10.1175/2008JCLI2105.1, 2008. 
O'Gorman, P. A. and Schneider, T.: The physical basis for increases in precipitation extremes in simulations of 21 st-century climate change, P. Natl. Acad. Sci. USA, 106, 14773-14777, 2009.

Palmer, T. N.: A nonlinear dynamical perspective on model error: A proposal for non-local stochastic-dynamic parametrization in weather and climate prediction models, Q. J. Roy. Meteor. Soc., 127, 279-304, 2001.

Palmer, T. N.: Towards the probabilistic Earth-system simulator: a vision for the future of climate and weather prediction, Q. J. Roy. Meteor. Soc., 138, 841-861, 2012.

Pendergrass, A., Coleman, D., Deser, C., Lehner, F., Rosenbloom, N., and Simpson, I.: Nonlinear response of extreme precipitation to warming in CESM1, Geophys. Res. Lett., 46, 10551-10560, 2019.

Peters, K., Jakob, C., Davies, L., Khouider, B., and Majda, A. J.: Stochastic Behavior of Tropical Convection in Observations and a Multicloud Model, J. Atmos. Sci., 70, 3556-3575, 2013.

Peters, K., Crueger, T., Jakob, C., and Mobis, B.: Improved MJOsimulation in ECHAM6.3 by coupling a Stochastic Multicloud Model to the convection scheme, J. Adv. Model. Earth Sy., 9, 193-219, 2017.

Plant, R. S. and Craig, G. C.: A Stochastic Parameterization for Deep Convection Based on Equilibrium Statistics, J. Atmos. Sci., 65, 87-105, https://doi.org/10.1175/2007JAS2263.1, 2008.

Rasch, P., Xie, S., Ma, P. L., Lin, W., Wang, H., Tang, Q., Burrows, S., Caldwell, P., Zhang, K., and Easter, R.: An overview of the atmospheric component of the Energy Exascale Earth System Model, J. Adv. Model. Earth Sy., 11, 2377-2411, 2019.

Rauscher, S. A., O’Brien, T. A., Piani, C., Coppola, E., Giorgi, F., Collins, W. D., and Lawston, P. M.: A multimodel intercomparison of resolution effects on precipitation: simulations and theory, Clim. Dynam., 47, 2205-2218, https://doi.org/10.1007/s00382015-2959-5, 2016.

Roca, R.: Estimation of extreme daily precipitation thermodynamic scaling using gridded satellite precipitation products over tropical land, Environ. Res. Lett., 14, 095009, https://doi.org/10.1088/1748-9326/ab35c6, 2019.

Roca, R., Alexander, L. V., Potter, G., Bador, M., Jucá, R., Contractor, S., Bosilovich, M. G., and Cloché, S.: FROGS: a daily $1^{\circ} \times 1^{\circ}$ gridded precipitation database of rain gauge, satellite and reanalysis products, Earth Syst. Sci. Data, 11, 1017-1035, https://doi.org/10.5194/essd-11-1017-2019, 2019.

Sakradzija, M., Seifert, A., and Heus, T.: Fluctuations in a quasistationary shallow cumulus cloud ensemble, Nonlin. Processes Geophys., 22, 65-85, https://doi.org/10.5194/npg-22-65-2015, 2015.

Simmons, A., Uppala, S., Dee, D., and Kobayashi, S.: ERA-Interim: New ECMWF reanalysis products from 1989 onwards, ECMWF Newsl., 110, 1-11, 2007.

Stone, D., Risser, M. D., Angelil, O., Wehner, M., Cholia, S., Keen, N., Krishnan, H., Obrien, T. A., and Collins, W. D.: A basis set for exploration of sensitivity to prescribed ocean conditions for estimating human contributions to extreme weather in CAM5.11degree, Weather Clim. Extremes, 19, 10-19, 2018.

Tang, Q., Klein, S. A., Xie, S., Lin, W., Golaz, J.-C., Roesler, E. L., Taylor, M. A., Rasch, P. J., Bader, D. C., Berg, L. K., Caldwell, P., Giangrande, S. E., Neale, R. B., Qian, Y., Riihimaki, L. D., Zender, C. S., Zhang, Y., and Zheng, X.: Regionally refined test bed in E3SM atmosphere model version 1 (EAMv1) and ap- plications for high-resolution modeling, Geosci. Model Dev., 12, 2679-2706, https://doi.org/10.5194/gmd-12-2679-2019, 2019.

Tang, S., Xie, S., Zhang, Y., Zhang, M., Schumacher, C., Upton, H., Jensen, M. P., Johnson, K. L., Wang, M., Ahlgrimm, M., Feng, Z., Minnis, P., and Thieman, M.: Large-scale vertical velocity, diabatic heating and drying profiles associated with seasonal and diurnal variations of convective systems observed in the GoAmazon2014/5 experiment, Atmos. Chem. Phys., 16, 14249-14264, https://doi.org/10.5194/acp-16-14249-2016, 2016.

Trenberth, K. E., Zhang, Y., and Gehne, M.: Intermittency in Precipitation: Duration, Frequency, Intensity, and Amounts Using Hourly Data, J. Hydrometeorol., 18, 1393-1412, https://doi.org/10.1175/jhm-d-16-0263.1, 2017.

Wang, Y.: A mapping file for the EAMv1 simulation output, Zenodo, https://doi.org/10.5281/zenodo.4543233, 2021.

Wang, Y. and Zhang, G. J.: Global climate impacts of stochastic deep convection parameterization in the NCAR CAM5, J. Adv. Model. Earth Sy., 8, 1641-1656, https://doi.org/10.1002/2016MS000756, 2016.

Wang, Y., Liu, X., Hoose, C., and Wang, B.: Different contact angle distributions for heterogeneous ice nucleation in the Community Atmospheric Model version 5, Atmos. Chem. Phys., 14, 1041110430, https://doi.org/10.5194/acp-14-10411-2014, 2014.

Wang, Y., Zhang, G. J., and Craig, G. C.: Stochastic convective parameterization improving the simulation of tropical precipitation variability in the NCAR CAM5, Geophys. Res. Lett., 43, 66126619, https://doi.org/10.1002/2016GL069818, 2016.

Wang, Y., Zhang, G. J., and He, Y. J.: Simulation of precipitation extremes using a stochastic convective parameterization in the NCAR CAM5 under different resolutions, J. Geophys. Res.Atmos., 122, 12875-12891, 2017.

Wang, Y., Zhang, G. J., and Jiang, Y.: Linking Stochasticity of Convection to Large-Scale Vertical Velocity to Improve Indian Summer Monsoon Simulation in the NCAR CAM5, J. Climate, 31, 6985-7002, https://doi.org/10.1175/jcli-d-17-0785.1, 2018.

Wang, Y., Zhang, G. J., Xie, S., Lin, W., Craig, G. C., Tang, Q., and Ma, H.-Y.: The EAMv1 simulation datasets for the manuscript, Zenodo, https://doi.org/10.5281/zenodo.3902998, 2020.

Wang, Y., Xia, W., Liu, X., Xie, S., Lin, W., Tang, Q., Ma, H.-Y., Jiang, Y., Wang, B., and Zhang, G. J.: Disproportionate control on aerosol burden by light rain, Nat. Geosci., 14, 72-76, https://doi.org/10.1038/s41561-020-00675-z, 2021a.

Wang, Y., Zhang, G. J., and Craig, G. C.: Stochastic convection code based on the DOE EAMv1, Zenodo, https://doi.org/10.5281/zenodo.4543261, 2021b.

Watson, P. A. G., Berner, J., Corti, S., Davini, P., Von Hardenberg, J., Sanchez, C., Weisheimer, A., and Palmer, T. N.: The impact of stochastic physics on tropical rainfall variability in global climate models on daily to weekly time scales, J. Geophys. Res., 122, 5738-5762, 2017.

Webb, M. J., Andrews, T., Bodas-Salcedo, A., Bony, S., Bretherton, C. S., Chadwick, R., Chepfer, H., Douville, H., Good, P., Kay, J. E., Klein, S. A., Marchand, R., Medeiros, B., Siebesma, A. P., Skinner, C. B., Stevens, B., Tselioudis, G., Tsushima, Y., and Watanabe, M.: The Cloud Feedback Model Intercomparison Project (CFMIP) contribution to CMIP6, Geosci. Model Dev., 10, 359-384, https://doi.org/10.5194/gmd-10-359-2017, 2017. 
Willmott, C. J. and Matsuura, K.: Smart interpolation of annually averaged air temperature in the United States, J. Appl. Meteorol., 34, 2577-2586, 1995.

Xie, P. and Arkin, P. A.: Analyses of Global Monthly Precipitation Using Gauge Observations, Satellite Estimates, and Numerical Model Predictions, J. Climate, 9, 840-858, https://doi.org/10.1175/15200442(1996)009<0840:AOGMPU>2.0.CO;2, 1996.

Xie, S., Cederwall, R. T., and Zhang, M. H.: Developing long-term single-column model/cloud system-resolving model forcing using numerical weather prediction products constrained by surface and top of the atmosphere observations, J. Geophys. Res., 109, D01104, https://doi.org/10.1029/2003JD004045, 2004.

Xie, S., Lin, W., Rasch, P. J., Ma, P. L., Neale, R., Larson, V. E., Qian, Y., Bogenschutz, P. A., Caldwell, P., and Cameron-Smith, P.: Understanding cloud and convective characteristics in version 1 of the E3SM atmosphere model, J. Adv. Model. Earth Sy., 10, 2618-2644, 2018.

Xie, S., Wang, Y., Lin, W., Ma, H., Tang, Q., Tang, S., Zheng, X., Golaz, J., Zhang, G. J., and Zhang, M.: Improved Diurnal Cycle of Precipitation in E3SM With a Revised Convective Triggering Function, J. Adv. Model. Earth Sy., 11, 2290-2310, 2019.

Zhang, G. J. and McFarlane, N. A.: Sensitivity of climate simulations to the parameterization of cumulus convection in the Canadian Climate Centre general circulation model, AtmosphereOcean, 33, 407-446, 1995.
Zhang, G. J. and Mu, M.: Simulation of the Madden - Julian Oscillation in the NCAR CCM3 Using a Revised Zhang-McFarlane Convection Parameterization Scheme, J. Climate, 18, 40464064, 2005a.

Zhang, G. J. and Mu, M.: Effects of modifications to the ZhangMcFarlane convection parameterization on the simulation of the tropical precipitation in the National Center for Atmospheric Research Community Climate Model, version 3, J. Geophys. Res.Atmos., 110, D09109, https://doi.org/10.1029/2004JD005617, 2005b.

Zhang, G. J. and Wang, H.: Toward mitigating the double ITCZ problem in NCAR CCSM3, Geophys. Res. Lett., 33, L06709, https://doi.org/10.1029/2005GL025229, 2006.

Zhang, G. J., Song, X., and Wang, Y.: The double ITCZ syndrome in GCMs: A coupled feedback problem among convection, clouds, atmospheric and ocean circulations, Atmos. Res., 229, 255-268, https://doi.org/10.1016/j.atmosres.2019.06.023, 2019. 